\title{
Sobre el Poder Ejecutivo
}

On the Executive Power

Sobre o poder executivo

Á propos du pouvoir exécutif

关于行政权力

\section{Raúl Gustavo Ferreyra ${ }^{1}$ | Universidad de Buenos Aires}

Revista Derechos en Acción ISSN 2525-1678/ e-ISSN 2525-1686

Año 4/Nº 11 Otoño 2019 (21 marzo a 21 junio), 29-90

DOI: https://doi.org/10.24215/25251678e269

ORCID: https://orcid.org/0000-0001-5089-8136

Recibido:15/03/2019

Aprobado: 25/04/2019

Resumen: El trabajo realiza un estudio constitucional del Poder Ejecutivo y del sistema presidencialista. Analiza la premisa según la cual las ordenaciones estatales que se deciden por el tipo de gobierno constitucional de sesgo presidencialista suelen exhibir determinada impotencia o fracaso mismo de la separación de poderes, alteración que favorece que el órgano ejecutivo se constituya en poder predominante. Reflexiona sobre el principio de división de poderes, los mecanismos para elegir a los presidentes, sus funciones y el lugar que ocupan los ciudadanos. Concluye afirmando que experiencia histórica del presidencialismo en América del Sud hacen pensar si acaso esa supremacía del poder ejecutivo no constituye, patéticamente, la causa de las causas de la inestabilidad institucional, del sometimiento y de la vulnerabilidad social.

Palabras claves: Constitución. Poder Ejecutivo. Presidencialismo.

Abstract: The work carries out a constitutional study of the Executive Power and the presidential system. It analyzes the premise according

\footnotetext{
1 Abogado. Profesor titular Derecho constitucional, Facultad de Derecho, Universidad de Buenos Aires (UBA). Doctor de la Universidad de Buenos Aires. Post doctor en Derecho, Facultad de Derecho (UBA) rgferreyra@derecho.uba.ar.

Contribución dedicada al Dr. Mario Leandro Casás.
} 
to which the state ordinances that are decided by the type of constitutional government of presidential bias usually exhibit certain impotence or even failure of the separation of powers, alteration that favors that the executive organ is constituted in predominant power. It reflects on the principle of division of powers, the mechanisms for electing presidents, their functions and the place occupied by citizens. He concludes that the historical experience of presidentialism in South America makes wonder whether this supremacy of executive power does not constitute, pathetically, the cause of the causes of institutional instability, subjugation and social vulnerability.

Keywords: Constitution. Executive Power. Presidentialism.

Resumo: 0 trabalho realiza um estudo constitucional do Poder Executivo e do sistema presidencialista. Analisa a premissa de acordo com a qual as ordenações estaduais que são decididas pelo tipo de governo constitucional com inclinação presidencialista costumam exibir certa impotência ou falha da separação de poderes, alteração que favorece que o corpo executivo se constitua em poder predominante. Reflete sobre o princípio da divisão de poderes, os mecanismos para eleger presidentes, suas funções e o lugar que ocupam os cidadãos. Ele conclui afirmando que a experiência histórica do presidencialismo na América do Sul sugere para o caso se essa supremacia do poder executivo não constitui, pateticamente, as causas da instabilidade institucional, da sujeição e da vulnerabilidade social.

Palavras-chave: Constituição. Poder Executivo. Presidencialismo.

Résumé: Le travail fait une étude constitutionnelle du pouvoir Exécutif et du système présidentiel. On analyse la prémisse selon laquelle les ordinations d'État décidées par le type de gouvernement constitutionnel avec tendance présidentielle, tendent à présenter une certaine impuissance ou un échec dans la séparation des pouvoirs, altération qui encourage que le pouvoir exécutif devienne le pouvoir dominant. On refléchit sur le principe de la division des pouvoirs, les mécanismes d'élection des présidents, leurs fonctions et la place occupée par les citoyens. On conclut en affirmant que l'expérience historique du présidentialisme en Amérique du Sud nous faire penser si cette suprématie du pouvoir exécutif ne constitue pas, pathétiquement, la cause de l'instabilité institutionnelle, de la sujétion et de la vulnérabilité sociale. 
Mot-clés: Constitution. Pouvoir exécutif. Présidentialisme.

\begin{abstract}
摘要: 该研究对行政权力和总统制进行了宪法研究。分析了这样一 个前提, 即由总统制偏见的宪政政府类型决定的国家统治倾向于 表现出某种无能或分权的失败, 有利于执行机构的改变构成了主导 权力。它反映了分权原则, 选举总统的机制, 其职能和公民所占的地 位。他最后肯定南美洲总统制的历史经验表明, 行政权力的这种至 高无上是否构成了制度不稳定, 服从和社会脆弱的原因。
\end{abstract}

关键字: 宪法, 行政权力, 总统制

\title{
I. Contexto
}

En la segunda década del siglo xxi los Estados de América del Sud se ordenan jurídicamente por una Constitución. Un código escrito que define la obediencia a reglas que asegurarían la determinación de las existencias en paz. Tales reglas, además, son discernidas y compuestas con bastante libertad por los representantes que obran por los ciudadanos -al menos, hasta cierto punto. Considero que las relaciones de igualdad social constituyen una asignatura pendiente. La exclusión, arraigada en un "fundamentalismo de mercado" 2 que por momentos arrasa, resulta imperdonable y un escándalo para la razón, porque retrasa el desarrollo y deriva en crisis desastrosas.

La eficacia de una Ley fundamental, como regla colectiva para la ordenación, depende del hecho de que los ciudadanos y los servidores públicos no pueden ni deben actuar en solitario. Deben hacerlo solidariamente por un objetivo común: su constante y leal realización.

La Constitución es un fundamento del Estado; concretamente, su cuarto elemento. En América del Sud las Constituciones fundamentan a los Estados y esta fundamentación, a su vez, se cumple por intermedio de cuatro reglas. Me refiero a la regla

2 ZafFaronı, E. Raúl: "Elogio del parlamentarismo", Le Monde diplomatique, año XIV, nº 160, Buenos Aires, 2012, p. 4. 
sobre la subordinación, la regla sobre la variación, la regla sobre la acción de los derechos fundamentales y la regla sobre la distinción de los poderes ${ }^{3}$.

El poder es único, pero distinguible en diversas ramas. Si bien hay un solo poder del Estado, hay varios departamentos o agencias que intentan su ejercicio con éxito y frustración, los que corren parejos y en suerte diversa. Por ello, para ejercer el poder se hace necesario su desgajamiento armónico en ramas, cuyos órganos constituidos han de cumplir las actuaciones correspondientes.

La distinción de las ramas del poder responde al hecho de que para su disciplina rigurosa resulta necesario su racional desmembramiento. El Derecho constituyente del Estado, la "política formalizada en reglas" ${ }^{4}$, disciplina al propio poder. Allí donde no existe razón jurídica para reglar una situación o relación, se estará en presencia de pura voluntad liberada, endemoniada e indisciplinada: el no Derecho. La proscripción de la razón jurídica por la voluntad del Estado anula al Derecho y origina un camino predispuesto hacia la autocracia.

La regla sobre la distinción del poder funciona de modo vertical y de modo horizontal. En el primero de los sentidos, opera a causa de la mayor descentralización estatal (poderes federales), mientras que en el segundo se lleva a cabo con la mayor centralización estatal (poderes unitarios). En medio de las tipologías federales y unitarias, corren los poderes que originan el modelo regional.

\footnotetext{
3 Las tres primeras reglas (subordinación, variación y acción) ya han sido descritas en Ferreyra, Raúl Gustavo: "Manifiesto sobre el Estado constitucional. Reglas fundamentales sobre raigambre y justificación de la comunidad estatal", $1^{\text {a }}$ parte, Revista de Derecho Público, nº 10, Presidencia de la Nación, Ministerio de Justicia y Derechos Humanos, 2015, Ediciones Infojus, Id SAIJ: DACF150418, pp. 37-124; $2^{a}$ parte, Revista de Derecho Público, $n^{0}$ 11, Presidencia de la Nación, Ministerio de Justicia y Derechos Humanos, 2015, Id SAIJ: RV000120, pp. 109-182. Otra versión, ampliada, actualizada y corregida, también ha sido publicada por la Editorial de la Universidad Abierta Latinoamericana, Medellín, 2017, 264 pp.

4 MaIER, Julio: "Derecho y democracia”, en Mientras estés conmigo, Ad-Hoc, Buenos Aires, 2017, p. 372.
} 
Considerada la regla sobre la distinción del poder en su comprensión horizontal, ella da lugar a los poderes constituyentes y a los poderes constituidos, por un lado, y a la separación de funciones de cada uno de los poderes constituidos, por el otro. La naturaleza, el alcance, los límites, los vicios y el control judicial sobre el poder constituyente, tanto el originario como el reformador, han sido objeto de análisis en otro texto 5 .

En lo concerniente a la distribución horizontal de funciones, el modelo sobre división del poder fue inventado en Europa, pero en América quedó codificado -por escrito-con la Constitución de Filadelfia de 1787. Al sistema de gobierno de Estados Unidos se lo denomina "presidencial" para distinguirlo del sistema parlamentario. En la Constitución estadounidense de 1787 se pueden ver recogidas, ampliadas y perfeccionadas las ideas expuestas por Montesquieu ${ }^{6}$ alrededor de cuarenta años antes, al punto de que cada uno de los tres departamentos a los que se encarga y atribuye la configuración del gobierno del Estado tiene claramente delineadas sus funciones específicas. Puede predicarse que la teoría pretende estipular un sistema de ordenación del poder con equilibrio y armonía, mediante frenos y contrapesos recíprocos a cada uno de ellos, con un plan de especialización de las funciones. Así, legislar, administrar y juzgar son banderas clave del itinerario constitucional estadounidense gestado en $1787^{7}$. Una bonita postal.

5 Ferreyra, Raúl Gustavo: Reforma constitucional y control de constitucionalidad. Límites a la judiciabilidad de la enmienda, Buenos Aires, Ediar, 2007. Obra también publicada en México, D.F. por Porrúa, 2008.

6 Montesquieu: Del espíritu de las leyes, Barcelona, Altaya, 1993 [original circa 1748], p. 115: "Hay en cada Estado tres clases de poderes: el Poder Legislativo, el Poder Ejecutivo de los asuntos que dependen del 'derecho de gentes' y el Poder Ejecutivo de los que dependen del derecho civil. Por el Poder Legislativo, el príncipe o el magistrado promulga leyes para cierto tiempo o para siempre, y enmienda o deroga las existentes. Por el segundo poder dispone de la guerra y de la paz, envía o recibe embajadores, establece la seguridad, previene las invasiones. Por el tercero, castiga los delitos o juzga las diferencias entre particulares. Llamaremos a éste Poder Judicial, y al otro, simplemente, Poder Ejecutivo del Estado".

7 La bibliografía sobre la Revolución, la Declaración de 1776 y la Constitución de EE.UU. de 1787 resulta vastísima y requiere un propio universo de ideas. Cito obras cuya inclinación 
Las ideas europeas respecto de la separación de las funciones estatales que predominaron durante los siglos xVII y xVIII no eran exactamente iguales a las que concretaron los patriotas que forjaron las repúblicas presidencialistas en América del Sur a partir del siglo xix. Aunque el movimiento constitucionalista liberal nació casi contemporáneamente a un lado y al otro del océano Atlántico -v. gr.: Independencia norteamericana en 1776 y Revolución francesa en 1789-, la fisonomía de cada proceso fue, desde luego, distinta. En cierta medida, en la concepción europea, separación o distinción de funciones estatales no habría de significar necesariamente atribuir a cada uno de los departamentos como interdependientes entre sí, y en perfecto equilibrio, una porción bastante simétrica y equivalente de la voluntad estatal. Tal concepción hizo que, de paso, quedara fuertemente mitigada -por no decir casi ausente- la idea de que la jurisdicción fuera uno de los posibles guardianes de la Constitución, nunca el único.

Los textos constitucionales en América del Sud reflejaron, en mayor o menor medida, la estructura de la Constitución de los Estados Unidos de 1787, según la cual la distinción de las ramas gubernativas significaba no sólo organizar sino también atribuir, con cierta equivalencia al menos en las letras jurídicas fundantes, el reparto de competencias de cada uno de

\footnotetext{
0 afición especial han sugerido determinada devoción en la escritura del argumento en el cuerpo principal del texto. Así, aunque no pueda afirmar que constituya una literatura fundamental, confieso su cualidad de indispensable: Reed Amar, Akhil: America's Constitution. A Biography, New York, Random House, 2006; Tushnet, Mark: Red, White and Blue. A Critical Analysis of Constitutional Law, Cambridge and London, Harvard University Press, 1988; ZInN, Howard: A People's History of the United States, New York, HarperCollins, 2003; Ackerman, Bruce: We the People, Foundations, I, London, The Belknap Press of Harvard University Press, 1991 y We the People, Transformations, II, London, The Belknap Press of Harvard University Press, 2001; BAllyn, Bernard: Los orígenes ideológicos de la Revolución norteamericana, Madrid, Tecnos, 2012; ToInet, Marie France: El sistema político de los Estados Unidos, México, Fondo de Cultura Económica, 1994; Tocoueville, Alexis de: La democracia en América, México, Fondo de Cultura Económica, 1992; TriBE, Laurence H: American Constitutional Law, 2. a ed., The Foundation Press Inc., New York, 1988 y Pritchett, Herman C.: La Constitución Americana, Buenos Aires, Tipográfica Editora Argentina, 1965.
} 
los poderes del Estado. La Constitución federal de los Estados Unidos de 1787 intenta poner en práctica las ideas sobre los controles y frenos recíprocos, con ejecución paralela de separación de las funciones estatales ${ }^{8}$.

Un estado de cosas fue la relación comunitaria establecida imperativamente por aquella Constitución de Estados Unidos?. Su modelo fue tenido muy en cuenta por los constituyentes que fundaron la inmensa mayoría de las repúblicas sudamericanas en el siglo xix, debido a una sencilla razón: era el único boceto que disponían en aquel momento. La impronta presidencialista con que implicaron a la configuración de sus sistemas de gobierno descansaba en el hecho peregrino de que existía, por entonces, un solo modelo republicano en circulación. Un modelo que gozó de un rápido e inusual prestigio, dado que dio lugar a un contexto de "creciente riqueza, libertad, éxito y poder [...] siempre que no se prestara demasiada atención a las víctimas" 10 .

Sin embargo, en el genuino desarrollo de la autoridad ejecutiva, no ha pesado sólo la notable influencia de los Estados Unidos. En la radiografía de los procesos constituyentes en el siglo xix, en América del Sud debe también contemplarse el caudillismo y el culto a la personalidad. Todo ello en liza con la ilusión de soluciones mágicas para enfrentar la profunda injusticia social originaria. Muchas Constituciones en América del Sud, en especial durante el siglo xIx, más que la fundamentación

8 V. Corwin, Edward S.: "The Constitution as Instrument and as Symbol", The American Political Science Review, Vol. 30, n 6, American Political Science Association, 1936, pp. 1071-1085.

9 Carlos Nino señaló que en el caso de los Estados Unidos, si bien el Poder Ejecutivo es una institución poderosa, sobre todo en el ámbito de las relaciones exteriores, está fuertemente condicionada por el Congreso gracias a su contralor financiero y a la injerencia en materia de designaciones, sea a través de la intervención constitucional del Senado, o mediante leyes que, sin quitarle al presidente su atribución en la materia, regulan esa atribución (Nino, Carlos: Fundamentos de Derecho Constitucional, Buenos Aires, Astrea, 1992, p. 520).

10 Chomsky, Noam: Réquiem por el sueño americano. Los diez principios de la concentración de la riqueza y el poder, México, D.F., Sexto Piso, 2017, p. 19. 
del Estado, intentaban alcanzar una dosis de paz estable y duradera, ante aciagos años de guerras civiles que las habían precedido. Por eso carecieron de vigencia, o ésta fue espontánea o episódica.

Como he adelantado, las nacientes repúblicas sudamericanas del siglo XIX, a juzgar por los varios centenares de modelos constitucionales insinuados desde entonces y hasta nuestros días $^{11}$, trataron de imitar el molde estadounidense de 1787. Sin embargo, el resultado ha sido bastante pernicioso, porque se copió la acumulación y hegemonía del poder estadounidense, pero sin dar lugar al diseño de controles efectivos ni atribuciones compartidas. Por lo tanto, se puede intuir que, desde el punto de vista de la "tecnología social en ciernes"12 que comporta el Derecho constitucional en América del Sur, la relación entre los poderes constituidos fue de cierta coordinación, ya que el liderazgo presidencial siempre pretende construir una hegemonía suficiente del poder estatal. Tanta concentración de tanto poder colocaría en entredicho las posibilidades de equilibrio constitucional; en particular, en la portada de su sistema (presidencialista), así como de su forma de gobierno (republicana).

\section{Tesis y estrategia argumentativa}

Aquí emprendo el camino sobre el poder ejecutivo, cuya encarnadura da lugar al presidencialismo, único modelo conocido para dar rienda al sistema de gobierno. En este sentido, presento la tesis primitiva:

Las ordenaciones estatales que se deciden por el tipo de gobierno constitucional de sesgo presidencialista suelen exhibir determinada impotencia o fracaso

\footnotetext{
11 Gargarella, Roberto: La sala de máquinas de la Constitución: Dos siglos de constitucionalismo en América Latina (1810-2010), Buenos Aires, Katz, 2014.

12 Bunge, Mario A.: Las ciencias sociales en discusión, Buenos Aires, Sudamericana, 1999, pp. 323 y ss.
} 
mismo de la separación de poderes, alteración que favorece que el órgano ejecutivo se constituya en poder predominante.

En desarrollos ulteriores intento su descripción y justificación, siempre en recto examen de sus bases normativas. Nótese, en la inteligencia de la tesis alumbrada, que se estudian dos aspectos determinados del presidencialismo. Por un lado, la concentración de funciones en la persona del líder del proceso; por otro, la posible descalificación del modelo por el predominio que ejerce el presidente sobre los otros poderes constituidos y también sobre los "mecanismos de decisión política en el Estado"13. La acumulación de funciones que puede asumir la presidencia se presenta como un obstáculo para la separación racional de las funciones gubernativas. En paralelo, la concentración desmedida de atribuciones ejecutivas se muestra irracional para imaginar la regularidad o estabilidad del orden constitucional.

Sostengo que la concentración de funciones puede ocasionar la inestabilidad institucional. Sin embargo, deseo aclarar que la inestabilidad presidencial no implica asumir esta retrodicción: que un sistema de gobierno parlamentario hubiese observado una mejor performance. No intentaré demostrar que el parlamentarismo es un modelo mejor que el presidencialismo, si acaso existiese un mecanismo o criterio indubitable para comprobar tal ejercicio. Mi aspiración resulta más acotada. No soy promotor de ningún modelo constitucional tradicional o en particular, aunque el hecho mismo de que un Estado adopte un sistema de gobierno parlamentario o presidencialista constituya la "decisión institucionalmente más significativa" ${ }^{14}$, porque tiene implicancias con las piezas de su

13 Carplzo, Jorge: El presidencialismo mexicano, México, D.F., Siglo Veintiuno Editores, 2002, p. 220.

14 Alegre, Marcelo: "Por una democracia sin presidentes", en AA.VV, Teoría y crítica del Derecho constitucional, t. I, “Democracia”, Buenos Aires, Abeledo Perrot, 2008, p. 45. 
orden constituyente y la calidad existencial de que podrían disfrutar sus ciudadanos.

Pretendo insinuar cómo se conforma y cómo se elige el poder del presidente y, eventualmente, hallar una justificación para que una sola persona disponga de semejante poder hegemónico, antes de hacer trizas la idea de separación de funciones y las expectativas sobre la racionalidad del obrar humano.

Siempre orientado por la tesis primitiva recién alumbrada, en la sección III esbozo rasgos del sistema presidencialista: una lista de criterios que podrían ser útiles para su descubrimiento y composición jurídica. Adelanto al lector que en este ensayo no resultará posible discernir, por completo, el interrogante “¿quién es un presidente?”. No existe un solo sistema de gobierno que lo regule, ni hay tampoco una sola persona que ejerza la suprema autoridad de la oficina ejecutiva de un Estado. Hay un presidente de Colombia, otro de Brasil y otro de Argentina, quienes, a su vez, han sucedido a otros presidentes y serán sucedidos por otros. "El ciudadano presidente en América del Sud" podría ser el título de un cuento o una novela, pero nunca una monografía o tesis jurídica, dada la diversidad de ciudadanos que han servido a la función y los esquemas que lo sostienen.

Pese a ello, por la vía de aproximaciones sucesivas, intento consolidar un criterio para definir el cuerpo del sistema de gobierno presidencialista. Además, aquí no realizo una tarea comparativa entre textos constitucionales. Sí hago referencia circunstancial a las Leyes fundamentales de la Argentina, del Brasil y de Colombia, "actualmente en vigor"15, por el hecho de

\footnotetext{
15 Conocer el pasado constitucional sitúa dentro de una fuente de interpretación perpetua y permite descubrir fragmentos inagotables e imprescindibles. En este ensayo, si bien no analizo la historia del constitucionalismo en la Argentina, en Brasil y en Colombia, comparto con el lector literatura fundamental que me ha acompañado al configurar estas escrituras. GalletI, Alfredo: Historia constitucional argentina, t. I y II, La Plata, Platense, 1972-1974; Restrepo Piedrahita, Carlos: Constituciones políticas nacionales de Colombia, Bogotá, Universidad Externado de Colombia, 1995; Bonavides, Paulo y Andrade, Paes de: História constitucional do Brasil, Brasilia, OAB, 2002.
} 
que tales instrumentos constitucionalizan las democracias de los tres Estados con mayor cantidad de ciudadanos en América del Sud. Ese significado mencionado y ningún otro -ni directo ni indirecto- hay que pueda atribuirse a la referencia escogida y la demarcación impuesta. Ésta carece por completo de pretensiones inductivas.

La Argentina posee uno de los sistemas constitucionales más antiguo en vigencia, si bien con rupturas y variaciones, desde 1853. Su Ley fundamental resulta considerada desde entonces y con las reformas de 1860, 1866, 1898, 1957 y, en especial, 1994: me refiero, así, a la Constitución federal de la República Argentina (CFA).

Brasil tiene el sistema constitucional ${ }^{16}$ que ordena el Estado con el territorio y la población más extensos, desde 1988. Con sus más de 90 enmiendas $^{17}$, se computa desde entonces ${ }^{18}$ la Constitución de la República Federativa del Brasil y sus reformas (CRFB 1988).

16 La descripción realizada del Derecho constitucional de Brasil se sustenta, básicamente, en las siguientes referencias: Bonavides, Paulo: Curso de Direito constitucional, San Pablo, Malheiros Editores, 2011; AA.VV.: Comentários à Constituição do Brasil, coordinación científica de Gilmar Ferreira Mendes, José Gomes Canotilho, Ingo Wolfgang Sarlet e Lenio Luiz Streck, San Pablo, Saraiva, 2014, 2380 pp.; y BARroso, Luis R.: Curso de Direito constitucional contemporâneo, San Pablo, Saraiva, 2012; Schwarcz, Lilia M. y Starling, Heloisa M.: Brasil: Una biografía, Buenos Aires, Debate, 2016.

17 V. Presidência da República: www.planalto.gov.br/ccivil_03/constituicao/emendas/emc/ quadro_emc.htm, consultado por última vez el 31/3/2018.

18 En Brasil, la Constitución de 1988 (con sus enmiendas) es el régimen jurídico elegido por sus ciudadanos. En el período 1988-2017, más allá de retrocesos y turbulencias, la economía, los negocios, la producción, el empleo y las finanzas han crecido de modo sostenido y con los mayores márgenes y porcentajes de toda su historia. También durante el período examinado, aunque no se ha curado de ninguna manera la distribución inequitativa de la riqueza y del acceso al disfrute de los bienes sociales, una importante cantidad de brasileños han podido salir de la indigencia y de la pobreza. La flagrante injusticia social no se ha eliminado ni sucederá en las próximas décadas. Sería injusto atribuir la dinámica de esas situaciones a la vigencia de una regla de juego básica, la Ley fundamental de 1988. La misma naturaleza ingenua se revelaría, acaso, si se pensara que el crecimiento descomedido del capital y la frágil reducción de la pobreza en nada se relacionan con la vigencia débil, pero vigencia al fin de cuentas, de una Constitución vulnerable. 
Colombia es un país herido por una epidemia de violencia y en el que el "uso de las armas" no es ni ha sido "monopolio de nadie"19: una enfermedad iniciada al menos desde 1946. Actualmente, con su Constitución Política y sus reformas (CPC $1991)^{20}$, representa un desafío mundial, porque la singularidad decisiva de su Ley fundamental constituye el bien colectivo más robusto para conquistar la paz.

El hecho de elegir algunos moldes constitucionales bordeados en esos tres países no implica trazar generalizaciones para el resto de los modelos que existen en América del Sur, ni denominadores comunes entre ellos mismos. Sin embargo, evitar las predicciones inductivas no desvanece la posibilidad de realizar comparaciones jurídicas, dado que todos los modelos elegidos por los diferentes Estados en América del Sud para el gobierno constitucional son, gracias a un juicio moderado, intensamente presidencialistas $^{21}$.

\section{Sobre el presidencialismo}

Las democracias constitucionales, guardadas bajo la forma republicana, ofrecen dos sistemas de gobierno: el presidencial y el parlamentario. Sin embargo, no hay un modelo presidencial que sea igual a otro. Tampoco existe un modelo parlamentario exactamente idéntico a otro. Cada modelo estatal apuntado para

\footnotetext{
19 Hobsbawm, Eric: ¡Viva la revolución!, Buenos Aires, Crítica, 2018, p. 431.

20 La descripción realizada del Derecho constitucional de Colombia tiene como referencias las siguientes obras: LleRAs de la Fuente, Carlos y Tangarife Torres, Marcel: Constitución política de Colombia. Origen, evolución y vigencia, t. I, II y III, Medellín, Biblioteca Jurídica Dike, Pontificia Universidad Javeriana-Ediciones Rosaristas, 1996; LleRAS DE LA Fuente, Carlos, Arenas Campos, Carlos A., Charry Urueña, Juan Manuel, Hernández Becerra, Augusto: Interpretación y génesis de la Constitución de Colombia, Bogotá, Cámara de Comercio de Bogotá-Departamento de Publicaciones, 1992; Melo, Jorge Orlando: Historia mínima de Colombia, Madrid, Turner, 2017.

21 Quizá fuese aplicable aquí la conocida sentencia de Tolstoi: “Todas las familias dichosas se parecen entre sí, del mismo modo que todas las desgraciadas tienen rasgos peculiares comunes" (Tolstoı, León: Ana Karenina, Barcelona, Juventud, 2015, p. 5).
} 
el sistema de gobierno republicano, en ambas especies, posee cualidades inherentes que lo distingue dentro del propio linaje.

Por ejemplo, Estados Unidos (Constitución de 1787 y sus enmiendas) y Colombia (CPC 1991 y sus reformas) adoptan el sistema de gobierno presidencial, pero cada una de sus Leyes fundamentales lo hace con semánticas prescriptivas distintivas. Resulta posible compararlas, pero no trazar simetrías entre ellas. Alemania (Ley Fundamental de Bonn de 1949 y sus reformas) e Italia (Constitución de 1947 y sus reformas) son repúblicas que adoptan modelos parlamentarios. Sin embargo, en cada una de ellas el sistema de gobierno resulta peculiar y hasta excluyente, si se ejerciere, acaso, una comparación finita de los moldes jurídicos respectivos. Además, entre el parlamentarismo y el presidencialismo navegan algunos sistemas de compleja nominación: el semipresidencial francés (Constitución de 1958 y sus reformas) o el colegiado suizo (Constitución del 2000).

Desde la invención del Estado constitucional producida con la Ley suprema de los Estados Unidos de 1787, no existe una patente que asegure que un modelo de sistema de gobierno ha de funcionar en cualquier lugar del mundo, con apego a las determinaciones normativas que lo autoricen a hacerlo. La Constitución, al igual que un vehículo, una computadora o un teléfono celular, es un objeto tecnológico, fruto de la razón y de la experiencia humanas. Sin embargo, su puesta en funcionamiento no es semejante al resto de los objetos mundanos mencionados. El manual de uso de una Constitución, a diferencia del de un vehículo, una computadora y un celular, es implementado por los ciudadanos y los servidores públicos.

En la búsqueda de una definición, la tesis de que "un sistema presidencial no es parlamentario y uno parlamentario no es presidencial" 22 , aunque es un avance irreprochable porque autoriza la exclusión mutua de los modelos confrontados, no

22 SARTORI, Giovanni: Ingeniería constitucional comparada. Una investigación de estructuras, incentivos y resultados, México, D.F., Fondo de Cultura Económica, 1996, p. 97. 
resulta del todo suficiente. Tampoco lo es afirmar que la diferencia entre el parlamentarismo y el presidencialismo resida en el hecho de que en el primero se privilegie la cooperación y se intente asegurar una armoniosa representación; mientras que en el segundo se afirme la gobernanza ejecutiva apoyada en el juicio de la mayoría, porque "el ganador se lleva todo"23 -añado: por un tiempo. Por último, poco se intuirá si se afirma que en los sistemas de gobierno parlamentarios se "comparte" el poder; mientras que en los sistemas de gobierno presidenciales eso no sucede, ya que prima el monólogo.

En la Argentina, la CFA dedica las cuatro secciones del Título primero "Gobierno federal" de su Segunda Parte, "Autoridades de la Nación", a la división del poder y la asignación de atribuciones a los órganos encargado de su ejercicio institucionalizado. Así, la sección primera comprende al "Poder Legislativo" (arts. 44 al 87); la sección segunda, al "Poder Ejecutivo" (arts. 88 al 107); la tercera, al Poder Judicial (arts. 108 al 119) y la cuarta, al Ministerio Público (art. 120).

En Brasil, La Constitución CRFB 1988 dedica los tres capítulos del Título IV a la "Organización de los Poderes". Así, el Capítulo I (arts. 44 al 75) se destina al "Poder Legislativo"; el Capítulo II (arts. 76 al 91), al "Poder Ejecutivo", y el Capítulo III (arts. 92 al 134), al "Poder Judicial".

En Colombia, la CPC 1991 define en su artículo 113 que son "Ramas del Poder Público, la legislativa, la ejecutiva y la judicial". En el párrafo siguiente, pese a ser un instrumento más moderno que el argentino y el brasileño, y quizá para aumentar la desconcentración de un ciudadano desprevenido, se dispone que "Además de los órganos que las integran existen otros, autónomos e independientes, para el cumplimiento de las demás funciones del Estado. Los diferentes órganos del Estado tienen funciones separadas pero colaboran armónicamente

\footnotetext{
23 LINZ, Juan: “Democracia presidencial o parlamentaria. ¿Hay alguna diferencia?”, en AA.WV.: Presidencialismo vs. Parlamentarismo. Materiales para el estudio de la Reforma constitucional, Consejo para la consolidación de la democracia, Buenos Aires, Eudeba, 1988, p. 40.
} 
para la realización de sus fines". Dentro del Título VI de la CPC 1991, se regula la "Rama Legislativa" (desde el art. 132 hasta el 187). En el ámbito del Título VII, se dispone la regulación de la "Rama Ejecutiva", (art. 187 hasta el 227). A su turno, la "Rama Judicial" resulta reglada en el Título VIII (art. 228 hasta el 257).

En toda comunidad democrática sus ciudadanos libres son soberanos. En el ejercicio y desarrollo de la soberanía de su libertad, no pueden existir otros límites que el respeto por igual libertad de cada otro ciudadano y las razonables exigencias para garantizar las existencias en paz. La agregación de las soberanías ciudadanas dispuestas para su autogobierno individual resulta el único modo para explicitar el autogobierno de una comunidad. Ningún ciudadano requiere de la división de su poder para autogobernarse. Esto resultaría incompatible con su irreductible soberanía individual. Sin embargo, el principio divisorio resulta una cuestión sin claudicaciones para ofrecer el autogobierno de Derecho para la comunidad. El desarrollo del autogobierno de los ciudadanos en una comunidad sólo puede ser explicitado en una democracia, con la justeza y con la destreza que se exhiban para dividir el poder comunitario que se empleará para la gobernanza.

La Argentina, Brasil y Colombia deciden, respectivamente, cada uno con sus propios matices, procesar la división del poder en sus casas republicanas ${ }^{24}$. No existe una división del poder superior a otra, ni una peor a otra. La idea de dividir el poder no tiene rival, desde que la concentración de su ejercicio carece de cualquier posibilidad de comprensión o justificación racional. Apréciese que de la idea que fulmina el rechazo enérgico de

\footnotetext{
24 Destaco aquí una curiosidad que delata la exquisita antigüedad del texto argentino. La extensión de su Ley fundamental es más breve que la colombiana y la brasileña. Sin embargo, en la arquitectura jurídica, la división del poder establecida para la Argentina ocupa alrededor de las dos terceras partes de las letras constituyentes de naturaleza permanente. Mientras que a idénticos fines y efectos, las letras brasileñas y colombianas, respectivamente, ocupan alrededor de una tercera parte de las letras constituyentes de sus Estados. No corresponde derivar de ello ninguna otra conclusión que la referida a la propia forma de escribir la literatura jurídica.
} 
cualquier fórmula sobre la indivisión del poder y que hace un apostolado por su realidad dividida, se derivan, decididamente, una afirmación y una negación. Así, se afirma el sostén tesonero sobre las reglas mismas y se debe negar la práctica de cualquier culto a la persona de cualquier líder. Quizá las reglas puedan ser objeto de cultivo, nunca las personalidades.

El presidencialismo ensayado en la Argentina, en Brasil y en Colombia -en cada país con sus cualidades propias- constituye un sistema de gobierno con poderes legislativos, ejecutivos y judiciarios separados, pero bajo la "batuta" de un director absoluto. Antes de su invención por el Derecho, por cierto, no había presidencialismo. Al ser objeto de trasplante desde su fuente original hacia América del Sur, aunque se dispuso con intransigencia significativa la idea de poder dividido, al mismo tiempo se decidió la instalación de una autoridad absoluta: el regio presidente.

Enumero una serie de cualidades elementales que permiten comprender al sistema presidencial, con arreglo a trazos que emergen de los países elegidos de América del Sud. Las pretensiones son limitadas: no intento la puesta en escena de una uniforme línea de acción dramática. Quiero enunciar, apenas, rasgos básicos para caracterizar un modelo presidencial. Advierto, además, que la fecundidad del modelo descansa en la conjugación de la totalidad de los criterios ilustrados para definirlo. Para ello realizo una exposición y un análisis detallado. Recuérdese que en la sección II menciono la "concentración de atribuciones" y la "inestabilidad del régimen". Más abajo, en la sección III, dentro de esta misma sección, llevo adelante un inventario de la presidencia, coronada con una definición. Luego de ofrecer una clasificación, brindo, por último, una comprensión acabada del asunto relativo a la estabilidad e inestabilidad del régimen presidencialista.

Basta por ahora, como simple adelanto, individualizar constitucionalmente las investiduras de cada uno de los presidentes de las repúblicas seleccionadas. La CFA ordena, en su artículo 87, que el "Poder Ejecutivo de la Nación será desempeñado por un 
ciudadano con el título de 'Presidente de la Nación Argentina'". La CRFB 1988 decide, en su artículo 76, que el Poder Ejecutivo es ejercido por el Presidente de la República, auxiliado por los Ministros del Estado. La CPC 1991, en su artículo 188, define que el "Presidente de la República simboliza la unidad nacional y al jurar el cumplimiento de la Constitución y de las leyes, se obliga a garantizar los derechos y libertades de todos los colombianos".

En un Estado constitucional, hacer la ley y realizarla son tareas fundamentales. Los congresistas son los hacedores por antonomasia de las leyes y los jueces algunos de sus realizadores. Bien se ha advertido que mientras que la tarea de configuración legal y la tarea jurisdiccional "denotan funciones de gobierno claramente definibles así como métodos enteramente constantes para su desempeño", el poder ejecutivo es "todavía indefinido en cuanto a su función" $"$. Hay una pizca de verdad: el poder presidencial es residual en un gobierno con departamentos separados; sin embargo, sus prerrogativas son tendencialmente dominantes respecto de los otros poderes constituidos.

La elección del líder del proceso constitucional se realiza, de modo directo y sin intermediaciones, por el cuerpo electoral y por un tiempo determinado. En la CFA, por ejemplo, se ordena lo siguiente:

Artículo 94. El Presidente y el vicepresidente de la Nación serán elegidos directamente por el Pueblo, en doble vuelta, según lo establece esta Constitución. A este fin el territorio nacional conformará un distrito único.

Artículo 96. La segunda vuelta electoral, si correspondiere, se realizará entre las dos fórmulas de candidatos más votadas, dentro de los treinta días de celebrada la anterior.

25 Conwin, Edward S.: El poder ejecutivo. Función y poderes 1787-1957. Atribuciones y funciones del Presidente de los EE.UU. a través de la historia y el análisis de la práctica constitucional, Buenos Aires, Bibliográfica Argentina, 1959, p. 5. 
Artículo 97. Cuando la fórmula que resultare más votada en la primera vuelta, hubiere obtenido más del cuarenta y cinco por ciento de los votos afirmativos válidamente emitidos, sus integrantes serán proclamados como Presidente y vicepresidente de la Nación.

Artículo 98. Cuando la fórmula que resultare más votada en la primera vuelta hubiere obtenido el cuarenta por ciento por lo menos de los votos afirmativos válidamente emitidos y, además, existiere una diferencia mayor de diez puntos porcentuales respecto del total de los votos afirmativos válidamente emitidos sobre la fórmula que le sigue en número de votos, sus integrantes serán proclamados como Presidente y vicepresidente de la Nación.

En la CRFB 1988 se dispone:

Artículo 77. A eleição do Presidente e do Vice-Presidente da República realizar-se-á, simultaneamente, no primeiro domingo de outubro, em primeiro turno, e no último domingo de outubro, em segundo turno, se houver, do ano anterior ao do término do mandato presidencial vigente.

$1^{\circ}$ A eleição do Presidente da República importará a do Vice-Presidente com ele registrado.

$2^{\circ}$ Será considerado eleito Presidente o candidato que, registrado por partido político, obtiver a maioria absoluta de votos, não computados os em branco e os nulos.

$3^{\circ}$ Se nenhum candidato alcançar maioria absoluta na primeira votação, far-se-á nova eleição em até vinte dias após a proclamação do resultado, concorrendo os dois candidatos mais votados e considerando-se eleito aquele que obtiver a maioria dos votos válidos.

Por su parte, en la CPC 1991 se ordena:

Artículo 190. El Presidente de la República será elegido para un período de cuatro años, por la mitad más uno de los votos que, de manera secreta y directa, depositen los ciudadanos en la fecha y con las formalidades que determine la ley. 
Si ningún candidato obtiene dicha mayoría, se celebrará una nueva votación que tendrá lugar tres semanas más tarde, en la que sólo participarán los dos candidatos que hubieren obtenido las más altas votaciones. Será declarado Presidente quien obtenga el mayor número de votos.

Recuérdese que en Colombia el sufragio para la elección del presidente de la República es voluntario o facultativo. En cambio, en Brasil y en la Argentina, para idénticos fines y efectos, es obligatorio.

El sistema de gobierno presidencial, ya sea en su versión argentina, brasileña o colombiana, al generar comicios directos para elegir al encargado del órgano ejecutivo, persigue una tentación irresistible: el encuentro "de" y "con" un oficial principal del pueblo. En la flora y fauna del régimen constitucional sudamericano, que opta por el modelo presidencial, no hay dudas acerca de las "mágicas" palabras generadoras: "frotar la lámpara y elegir un oficial del pueblo".

El mecanismo plebiscitario establecido en la Constitución de Francia de 1848 generó una "profunda repercusión en América Latina" ${ }^{26}$. Aquella Constitución fue la primera Ley fundamental que dispuso el sistema de gobierno presidencial en Europa y su elección directa por el cuerpo electoral ${ }^{27}$. Aunque muchos

26 ValAdÉS, Diego: "Formación y transformación del sistema presidencial en América Latina: Una reflexión sobre el ius constitutionale commune latinoamericano", en AA.VV.: Estado constitucional, derechos humanos, justicia y vida universitaria. Estudios en homenaje a Jorge Carpizo, t. IV, vol. 2, "Estado constitucional”, México, D.F., UNAM, IIJ, 2015, p. 835.

27 Para ratificar esta aserción basta leer algunos artículos de la Constitución de la Segunda República Francesa, del 4 de noviembre de 1848. Me he permitido enfatizar en cursiva la naturaleza del sufragio y del cargo ejecutivo como las condiciones de elegibilidad y el propio procedimiento de elección.

"Art. 24. El sufragio es directo y universal. La votación es secreta".

"Art. 25. Son electores, sin condición de censo, todos los franceses con veintiún años de edad, y que gocen de sus derechos civiles y políticos".

Art. 43. El pueblo francés delega el Poder ejecutivo a un ciudadano que recibe el título de presidente de la República". 
modelos constitucionales en América del Sud durante el siglo XIX siguieron el modelo estadounidense de elección presidencial indirecto, hoy se trata, prácticamente, de un modelo abandonado. Actualmente, la abrumadora mayoría de los Estados sudamericanos apelan, para elegir a su presidente, al modelo constitucional francés, fundado en el principio mayoritario para escoger un líder. Este modelo, sin dudas, legitima al oficial del pueblo que se ha de elegir. Empero, al mismo tiempo, genera un nacimiento cada cuatro años de un nuevo "animal político": el "monopresidente".

La segunda vuelta electoral persigue una calificación, por las urnas, de un candidato, aunque por lo general se presenta un binomio: el vicepresidente que acompaña en la fórmula política. En los modelos examinados, además, a la segunda vuelta electoral sólo concurrirán las dos fórmulas para presidente y vicepresidente que hayan obtenido el primero y el segundo lugar, respectivamente, en la escala de preferencias de los votos contabilizados en la primera ronda.

Los sistemas electorales no son ni buenos ni malos. Son modelos que se escogen para congregar las preferencias ciudadanas y permitir que los ciudadanos que integran el pueblo puedan expresarlas individualmente. No haré aquí una tipología de los sistemas electorales, si acaso ello fuese factible, aunque cabe mencionar que el modelo elegido -sea de naturaleza mayoritaria o de naturaleza proporcional- tendrá incidencia cabal sobre el resultado de la elección ciudadana. No existen

\footnotetext{
“Art. 45. El presidente de la República es elegido por cuatro años. Sólo será reelegible después de un periodo de cuatro años. Tampoco pueden ser elegidos después de él, dentro del mismo periodo, ni el vicepresidente, ni ninguno de los parientes o aliados del presidente, hasta el sexto grado inclusive".

"Art. 46. La elección tiene lugar de pleno derecho el segundo domingo del mes de mayo. En el caso de que, por causa de deceso, dimisión o por cualquier otra causa, el presidente fuera elegido en otra fecha, sus poderes expirarían el segundo domingo del mes de mayo del cuarto año siguiente al de su elección. El presidente es nombrado, con voto secreto y por mayoría absoluta de los votantes, por sufragio directo de todos los electores de los departamentos franceses y de Argelia".
} 
sistemas electorales mayoritarios puros ni sistemas electorales de representación proporcional puros, porque la inspiración de cada modelo se vincula con la aplicación que merezca en cada Estado. Dicha ponderación, por cierto, no puede hacer que se desconozcan sus objetivos, dado que en los sistemas electorales "mayoritarios", por regla, existirá un "ganador que se quedará con todo"28; mientras que en los de sistemas de "representación proporcional" el "triunfo es compartido y sencillamente se requiere un porcentaje electoral". Por ende, se puede predicar que en los sistemas mayoritarios el elector debe dirigir, por regla, su preferencia hacia un candidato individual, mientras que en los sistemas proporcionales, por regla, la canalización del voto se orientará hacia la lista de un partido político.

El sistema electoral para la elección presidencial, con doble vuelta electoral, escogido en la Argentina, en Brasil y en Colombia constituye un modelo de inspiración mayoritaria. El elector sufragará, casi con seguridad, dos veces. En todos los casos se persigue el encuentro de un "vencedor indiscutible"29. En Brasil y en Colombia los enunciados constitucionales configuran un premio que se compadece con determinada consideración aritmética: los ganadores, para quedar investidos en tal carácter, deben alcanzar la mayoría absoluta de los sufragios ciudadanos. Una "sabia exigencia"30 jurídica. En cambio, en la Argentina se ha constitucionalizado una distorsión singular, desde que bastaría acumular una mayoría relativa -el $40 \%$ de los sufragios- para ser computado como premio electoral, a condición de que el primer binomio hubiese obtenido una ventaja de "diez puntos porcentuales respecto del total de los votos sobre la fórmula que le sigue en número de votos" ${ }^{31}$.

\footnotetext{
28 SARTORı, Giovanni: ob. cit., p. 15.

29 Ibíd., p. 17.

30 Ibíd., p. 25.

31 Quizá, el poder constituyente reformador en la Argentina (1994) para alejarse de la certeza indubitable que desde tiempo inmemorial proviene de la aritmética y rige el mundo, se haya inspirado en el verso "Todo es igual; nada es mejor" ("Cambalache", [1934]), aunque
} 
En el primer turno electoral, en la Argentina, en Brasil y en Colombia, se presentarán una decena -o más- de candidatos para presidente de la República. En esa instancia electoral, el ciudadano se encuentra con suficiente cercanía a determinadas propuestas encaradas por el candidato. El programa electoral ofrecido, por lo tanto, podría llegar a constituir -repito, en la primera vuelta electoral- un elemento de cohesión de la personalidad ciudadana del sufragio. Quizá, en esa primera ronda, el candidato obtenga la "mayoría absoluta" requerida constitucionalmente en Brasil y en Colombia, o la "mayoría relativa" prescrita en la Argentina. Así, no existiría segunda vuelta para elegir presidente. Todos los candidatos, aunque no lo digan, se preparan para una segunda vuelta.

En la Argentina, desde la instauración del mecanismo en 1994 hasta el presente, de los seis turnos para elegir presidente (1995, 1999, 2003, 2007, 2011 y 2015), sólo en uno de ellos existió segunda vuelta (2015).

Brasil, con su Constitución de 1988, ha elegido presidente en siete ocasiones. Así, se votó en 1989, 1994, 1998, 2002, 2006, 2010 y 2014; en cinco de los turnos electorales se produjo la segunda vuelta (1989, 2002, 2006, 2010 y 2014).

En Colombia, a partir de su Ley fundamental de 1991, se ha elegido presidente en seis ocasiones (1994, 1998, 2002, 2006, 2010 y 2014), y en cuatro de los comicios se produjo la segunda vuelta $(1994,1998,2010$ y 2014).

Si se sumasen los turnos para escoger presidentes en los tres países enfocados, el resultado sería 19 comicios $^{32}$; en diez de ellos se produjeron segundas rondas electorales, con la

sin comprender el confeso sentido de amarga y desilusionada crítica institucional y social de aquel tango argentino de Enrique S. Discépolo.

32 Un escritor nunca finaliza su tarea porque el acto de escribir es infinito. Las escrituras, sin ambages, pueden quedar definidas y mostrar determinado grado de conclusión. Estas letras quedaron concluidas el 31/3/2018. Para el 27/5/2018 se encuentra prevista la primera vuelta para elegir presidente de la República de Colombia: 2018-2022; la segunda vuelta se encuentra contemplada para el 17/6. En Brasil se elegirá presidente de la República para 
salvedad de que en la Argentina, en 2003, uno de los candidatos no se presentó a la segunda vuelta porque presumía que perdería (así se evitó el gasto pero no el aumento de su descrédito ciudadano). Además, fruto de las reelecciones, en esos 19 turnos fueron elegidos trece presidentes, sólo tres de ellos obtuvieron más del $50 \%$ de los sufragios en la primera vuelta electoral: Cristina Fernández de Kirchner (2011); Fernando Henrique Cardoso, en sus dos ocasiones (1994, 1998); y Álvaro Uribe Vélez, también en sus dos oportunidades (2002, 2006).

Ahora bien, esa tendencia unificadora o cohesiva que el elector puede demostrar en apoyo a un programa de gobierno posee fecha de vencimiento: la noche en que se brindan los resultados de la primera ronda. En ese momento desaparecen del muestrario una gama importante de las preferencias de las que dispusiere el ciudadano. En la Argentina y Brasil, donde el sufragio es obligatorio, el ciudadano se encuentra ante el panorama de lo "debido": tendrá la obligación de sufragar, en la segunda ronda electoral, por uno de los dos candidatos que competirán en ella. Tales aspirantes a la presidencia, probablemente, no hayan sido elegidos en la primera vuelta por el ciudadano, quien deberá optar entre uno de ellos para cumplir con sus deberes constitucionales.

Desde la noche en que se hayan escrutado provisoriamente los votos y conocido los resultados de la primera ronda electoral hasta el cierre de campaña previsto para la segunda vuelta, se ha de originar otro momento extraordinario. Los dos candidatos a presidente de la República habrán de provocar el apoyo de los votantes que no se los hayan confiado en la primera ronda. Los doctrinarios que apoyan honestamente este modelo mayoritario, con segunda vuelta electoral, guardan ilusiones. Por ejemplo, que existirá un diálogo con los ciudadanos, renovado o apuntalado por acuerdos sobre la futurible gobernanza, en este breve y nuevo momento de campaña. Nada de eso sucederá

cubrir el período 2019-2023, en los comicios previstos para el 7/10/2018; la segunda ronda electoral ha sido fijada para el 28/10. 
porque -reitero- se votará a una persona o a otra, exista o no exista debate entre los dos candidatos. Se podría contestar que un candidato, en algunas cuestiones, es más progresista que el otro, que se muestra más conservador. También que un candidato posee ideas más liberales y el otro, ideas más socialistas.

Penosamente, la segunda vuelta electoral no favorece, en la práctica, la construcción de acuerdos sustentables ni la discusión de programas e ideas que, con vigor, ayudarían a racionalizar ${ }^{33}$ el sistema presidencial ${ }^{34}$. La segunda ronda aumenta de manera decisiva las pasiones electorales, a veces hasta el paroxismo de desconocer al otro candidato. Un ejercicio recíproco de las campañas: buscar un triunfo jamás debería excluir o negar al adversario. En efecto, este incremento de las pasiones por encima de las razones le hará creer al presidente que resulte electo que se encuentra respaldado por una mayoría real de ciudadanos.

El presidente, a cargo del poder ejecutivo, es una persona que reunirá una concentración inusitada del poder, fruto de la misma naturaleza escogida para su elección vía sufragio universal. Por lo general, además, será electo por una dedicada mayoría absoluta de ciudadanos. Frente a los ciudadanos, en principio, sería "responsable políticamente" ${ }^{35}$, hasta nuevo aviso electoral o acontecimiento fatal que impida la prosecución del mandato.

La elección directa del presidente, con los alcances y las condiciones descritas, dispone una buena cuota de legitimación

33 E. Raúl Zaffaroni se pregunta “ ¿Es racional el presidencialismo? ¿Hasta dónde es racional un sistema que concentra las funciones del jefe de Gobierno y del jefe de Estado en una persona? En América Latina suele defenderse este superpoder con el argumento de una supuesta necesidad de Ejecutivos fuertes porque estamos habituados al caudillismo, lo que encierra varias falacias. Es verdad que hay personas con particulares dotes de empatía con la ciudadanía, pero esa condición política es personal y no la otorga ninguna ley. Quien la posea se destacará en cualquier sistema. Se podría reformular el viejo adagio: Lo que natura non da la Constitución non presta". ZafFaronI, E. Raúl: "Elogio del parlamentarismo", ob. cit., p. 6. 34 ValAdÉs, Diego: El gobierno de gabinete, Buenos Aires, UNAM-Rubinzal-Culzoni, 2008, p. 13. 35 Nogueira Alcalá, Humberto: "Los presidencialismos latinoamericanos", en AA.VV.: Estado constitucional, derechos humanos, justicia y vida universitaria. Estudios en homenaje a Jorge Carpizo, Estado constitucional, t. IV, vol. 2, México, D.F., UNAM, IIJ, 2015, p. 404. 
originaria al escogido ${ }^{36}$. Repárese, por cierto, que dicha justificación en el origen, gracias a la ingente movilización ciudadana, podría cultivar el personalismo: un vicio que le permitiría al presidente "abusar del poder, como pasó con tantos personajes sin más visión ni competencia" ${ }^{37}$ que la necesaria para seguir ligados al cargo.

Dentro del marco de la elección directa por los ciudadanos, la cuestión de la duración del mandato también posee un matiz determinante. Hay que elegir un presidente para liderar el proceso constitucional por determinada e inflexible cantidad de años. No importará, luego, si existieron maquinaciones, engaños o un notable abuso del poder, porque las atribuciones son extensas y relevantes. Todo se reduce a eso: elegir directamente a una persona, investida con toda la magistratura y a delegar en él poderes suficientemente hegemónicos por cuatro años (esa es la duración en la Argentina, Brasil y Colombia), con posibilidades inmensas para reelegir, como es el caso de la habilitación constitucional consentida, actualmente, en la Argentina (art. 90, CFA) ${ }^{38}$ y en Brasil (arts. 82 y 14, ap. 5, CFRB 1988) ${ }^{39}$. Felizmente,

36 La última elección para escoger presidente y vicepresidente de la República que se realizó en Brasil fue en 2014. El binomio triunfador, en la segunda vuelta electoral, alcanzó casi 55.000 .000 de votos, expresión de más del $51 \%$ de los sufragios válidos. En la Argentina la última elección presidencial para elegir presidente y vicepresidente de la República se cumplió en 2015. El binomio que alcanzó el éxito en la segunda vuelta electoral obtuvo casi 13.000.000 de sufragios, expresión más del $51 \%$ de los votos ciudadanos.

37 Bunge, Mario: "El presidencialismo, un verdadero cáncer", Buenos Aires, La Nación, 21/7/2009, disponible en https://www.lanacion.com.ar/1152736-el-presidencialismo-unverdadero-cancer, consultado por última vez el 7/6/2018.

38 En el art. 90 de la CFA se dispone que "El Presidente y vicepresidente duran en sus funciones el término de cuatro años y podrán ser reelegidos o sucederse recíprocamente por un sólo período consecutivo. Si han sido reelectos, o se han sucedido recíprocamente, no pueden ser elegidos para ninguno de ambos cargos, sino con el intervalo de un período" (énfasis agregado).

39 La CRFB 1988, según su texto originario, prohibía la reelección presidencial. La autorización fue dispuesta en 1997. Hoy, la reelección presidencial se rige por la conjugación de los arts. 82 y 14 , ap. 5.

"Art. 82. 0 mandato do Presidente da República é de quatro anos e terá início em primeiro de janeiro do ano seguinte ao da sua eleição". 
en la CPC 1991, a partir de una reforma instituida en 2015, se ha prohibido la reelección en el artículo 197 reformado.

Al elegirse un presidente en los tres países analizados, dicho servidor público ejercerá la autoridad suprema ejecutiva, monologada y a discreción. De este modo, se esperaría un juicio equilibrado, ponderado y racional de una sola persona las 24 horas de cada uno de los días que durará su servicio en los cuatro años determinados para el mandato constitucional. Ciertamente, se trata de una vara muy alta, posible en la lógica pero imposible en la rutina empírica. La experiencia de 2.500 siglos demuestra que no hay animal racional que posea tal virtud. Quizá, en el futuro, la inteligencia artificial asegure otra alternativa.

Durante su período, el presidente empleará gran parte de su energía, en el caso de la Argentina y de Brasil, para robustecer sus posibilidades de reelección. En tales casos, durante su "primer período" insinuará los siguientes mensajes: 1) que cuatros años es muy poco para cumplir la tarea de reformas que desea realizar, porque ha recibido la economía devastada, las finanzas angostadas, el empleo en caída, la educación y la salud pública desatendidas, las relaciones internacionales descuidadas y, en fin, el buen vivir en crisis; 2) que se compromete a cumplir el plan de reformas en un segundo período; 3) que en la comunidad no existe otra persona enteramente capaz, como sí lo es él, para liderar la providencia o el buen vivir comunitario; 4) que se postula para la reelección en el cargo ejecutivo para un nuevo período, en una disputa política que centralizará el último tercio de existencia de su primer mandato para el cual fue constitucionalmente elegido.

El tiempo determinado para el cargo ejecutivo, además, constituye un elemento que hace a la rigidez del modelo y dificulta las capacidades para la maniobra y la búsqueda del

"Art. 14, ap. 50: 0 Presidente da República, os Governadores de Estado e do Distrito Federal, os Prefeitos e quem os houver sucedido, ou substituído no curso dos mandatos poderão ser reeleitos para um único período subseqüente" (énfasis agregado). 
consenso político. El presidente, al carecer de la facultad para disolver las Cámaras del Congreso, tendrá pocas oportunidades para resolver disputas políticas, si es que estas últimas destellan, auguran o denotan ostensible complejidad.

No hay que echar las culpas a los inventores del poder presidencial. Las prerrogativas de este oxímoron "príncipe republicano" 40 fueron imaginadas para instituciones separadas que deben compartir el gobierno de la comunidad, pero que muchas veces competirán entre sí. Para aliviar esa competencia política, quizá, se pensó que departamentos compartimentados, con potestades exclusivas y descritas con rigidez semántica, favorecerían el clima de gobierno. En el sistema de gobierno presidencial, la práctica dominante o débil de los presidentes provoca que esa rigidez, en muchas ocasiones, deje atrapado al "príncipe" en un laberinto del que ni siquiera podrá salir por arriba, como ha enseñado el poeta argentino ${ }^{41}$.

El presidencialismo es un sistema regido, sustantivamente, por la confianza ciudadana expresada en un comicio. Ello significa que por vía de principio no existe el voto de confianza institucional o acuerdo parlamentario sustentable, que sí se establece en los sistemas de gobierno parlamentario.

El presidente rinde cuentas, alentado por la fuerza normativa de lo fáctico, básicamente, ante el electorado, cuerpo que le puede renovar su confianza o no repetirla en una nueva elección. Las elecciones presidenciales, sobre todo cuando aspira a su reelección en el cargo, constituyen verdaderos bancos de prueba para las políticas públicas que se desplegaron $\mathrm{y}$, en

\footnotetext{
40 La palabra "príncipe" ofrece una destacable polisemia. Aquí, se la utiliza en la siguiente orientación semántica, según define el Diccionario de la Lengua Española: “. . que por su excelencia sobresalen entre los demás de su clase o especie". Ciertamente, en una "república" en la que todos sus ciudadanos son igualmente libres, no debería existir tal lugar para que un individuo sobresaliese por su poder. Sin embargo, en las democracias presidencialistas, el presidente, al ser elegido del modo en que se escoge para hacerlo y bajo las condiciones que asumirá su liderazgo, es autorizado a emplear tal poder, garantizado, al menos, desde la simple, alusiva e inofensiva canalización que sugiere la metáfora.

41 Marechal, Leopoldo: Laberinto de amor, Buenos Aires, Ediciones Sur, 1936, p. 48.
} 
especial, las que se prometen en el futuro. Esto no significa que no existan mecanismos de responsabilidad política en la propia Constitución. El presidencialismo alberga un régimen para la destitución del jefe del ejecutivo, cuyas líneas principales fueron esbozadas en el impeachment contemplado en la Constitución de los Estados Unidos de 1787 (art. I, $3^{\text {a }}$ sección).

El presidente de la Argentina puede ser destituido por juicio político; acto atribuido al Senado de la República (art. 60, CFA); cabe aclarar que en toda la historia republicana ningún presidente ha sido destituido por esta vía congresual. En Brasil se han desarrollado casos asombrosos de "processo" (art. 51, inc. $1^{\circ}$, CRFB 1988). Su historia más reciente muestra el juicio celebrado en 1992 contra el presidente Fernando Collor de Mello. Más reciente, en 2016, la presidenta Dilma Rousseff fue enjuiciada y sancionada con la "pérdida del cargo", decisión trazada por mayoría en el Senado (art. 52). Por su parte, en Colombia la destitución también la dispone el Senado, según se ordena en el artículo 175, apartado $2^{\circ}$ de la CPC 1991.

La acusación constitucional que puede originar un juicio político se funda, por regla, en el mal desempeño del cargo o en el abuso del poder ${ }^{42}$. Sin embargo, con frecuencia, los textos constitucionales son exageradamente genéricos al definir la causal que originaría el juicio de residencia del titular del poder ejecutivo. El principal problema para la radicación de un juicio político no reposa tanto en la causal configurada para destituir y estimular el proceso. Los presidentes tienen mayorías congresuales relevantes, que se integran por miembros de sus partidos o fuerzas políticas aliadas, razón por la cual en estas mayorías descansa la indisponibilidad segura del enjuiciamiento político. La denuncia, el juicio y la remoción política son un "negocio muy difícil" 43 en el sistema presidencialista, en virtud de que

\footnotetext{
42 V. Bidart Campos, Germán: “El abuso 'de' Derecho en el Derecho Público”, Academia Nacional de Derecho y Ciencias Sociales (separata), Buenos Aires, La Ley, 2003.

43 Ackerman, Bruce: La nueva división de poderes, México, D.F, Fondo de Cultura Económica, 2007, p. 42.
} 
la mayoría congresual que se determina para su admisibilidad y procedencia reviste naturaleza extraordinaria y difícil de alcanzar.

En el régimen examinado, el presidente concluye su tarea por la finalización temporal de la designación. El gobierno ejecutivo del Estado es una atribución del presidente y, salvo que sea destituido por el Congreso (hecho que casi nunca sucede), dimita o sea declarado incapaz o fallezca, culminará su tarea constitucional.

No es una propuesta de constitutione ferenda, ni valiosa en sí misma porque se juzgase inidóneo al sistema presidencial. Sin embargo, para ser coherente dicho modelo de gobierno, dado que dispone de la elección directa del jefe del gobierno y jefe del Estado -reunión que se produce en la unidad de una persona-, debería contemplar la posibilidad concreta de la revocatoria del mandato del titular del órgano ejecutivo ${ }^{44}$. Pienso, así, respecto del derecho de un porcentaje razonable del electorado a requerir la revocación del mandato fundándose en causas relacionadas con el mal desempeño o el desempeño inconstitucional del presidente. Si éste resulta elegido de manera directa por el cuerpo electoral, no se alcanzarían a vislumbrar las razones que inhibirían un proceso de destitución que tenga fuente semejante de nutrición. En ese "mano a mano" constitucional, la petición ciudadana de revocatoria del mandato del presidente, si prosperase, podría ser sometida a la participación obligatoria del cuerpo electoral, por ejemplo, mediante la vía de referéndum o plebiscito, o la que se escogiese.

En cuanto a sus facultades, el presidente elegirá a sus colaboradores, determinará la política y la relación con las fuerzas

\footnotetext{
44 La última presidente electa en la historia constitucional de Brasil, Dilma Rousseff, necesitó en 2014, para su reelección, más de 55 millones de votos ciudadanos para acceder al cargo. Nótese que bastaron, en 2016, 61 votos de servidores públicos, senadores de la República, para invocar la pérdida de su investidura constitucional obtenida con legitimación en las urnas. No hay ni paralelismo ni congruencia en las formas constitucionales. Si se asume la elección directa, pareciera que la pérdida del cargo constitucional debería asumir mecanismos semejantes de decisión ciudadana sin intermediarios ni vacilaciones.
} 
políticas. Además, el presidente de la República en Colombia "nombra y separa libremente a los Ministros del Despacho" (art. 189, inc. $1^{\circ}$, CPC 1991). Una situación análoga se comprueba en la Argentina (art. 99, inc. $7^{\circ}$, CFA) y también en Brasil (art. 84, inc. $1^{\circ}$, CRFB 1988). La atribución concedida a la autoridad suprema ejecutiva para nominar y exonerar a sus ministros no se ve menguada por el hecho de que el Congreso pueda citar a dichos colaboradores presidenciales o éstos se encuentren obligados por la Ley fundamental a dar informes sobre la gestión o, eventualmente, sean incitados a la renuncia a su cargo.

El poder de nominación y designación del presidente es casi omnímodo, porque completa las parcelas de su gabinete conforme su leal saber y entender, sin injerencia ni acuerdo ni recomendación congresual. De mediar la presencia de miembros del Congreso en el ámbito de la decisión, ella no afecta la atribución del presidente para nominar y designar, con exclusividad, un reemplazante. Tampoco se produce un deslizamiento de la autoridad del presidente por la renuncia de un ministro o su cuestionamiento por el Congreso. No hay, en este sentido, en el ámbito del sistema de gobierno presidencial, un respaldo congresual para los ministros del ejecutivo. Tampoco existe un deterioro supino del ejercicio del poder presidencial como consecuencia de la caída en desgracia política de uno o varios de sus ministros. El gobierno del presidente seguirá adelante. El faro que ilumina su itinerario emerge de sus propias convicciones y experiencia.

La unidad del poder del presidente constituye el fundamento del sistema de gobierno. La unidad no significa que el presidente no tenga colaboradores. La unidad expresa que las facultades confluyen en la singularidad individuada en su persona. Las atribuciones constitucionales del presidente son indivisibles, condición indispensable para no destruir ni alterar su genuino poder.

El poder en el Estado constitucional se descubre en su energía suprema. Quizá, para hacer que prosperase dicho poder 
y que fuese enérgico, se imaginó la unidad y concentración de las facultades ejecutivas. Por eso -intuyo-, al inventarse la institución presidencial en 1787 , se creyó conveniente que la autoridad de un solo hombre facilitaría las decisiones gubernativas de naturaleza ejecutiva. En dicha inteligencia queda captada la idea de que la "unidad tiende a la energía" "As. Así, pues, por simple derivación, se distinguirá, en otros servidores públicos, un mero rol secundario, siempre detrás de las bambalinas, como consejeros, pero sin dominio de los hechos ni representación popular directa. La búsqueda de un "buen gobierno" 46 , eficaz y seguro, sin dudas, animó la comprensión ensayada respecto de la unidad de la energía del poder presidencial.

La concepción de la unidad del poder presidencial no nació en un marco determinado por la lucha entre las clases sociales. En el génesis del poder del presidente se comprende la necesidad de proteger a una comunidad de alrededor de cuatro millones de personas: un estado incipientemente capitalista ${ }^{47}$. Para su conducción política, se buscó un presidente con poderes suficientes para garantizar la seguridad respecto de ataques desde el exterior, junto con la tutela de la propiedad de quienes ya habían adquirido sus bienes o de quienes lo podrían lograr, con bastante certeza, en el futuro. Así eran los Estados Unidos en los momentos de su fundación constituyente.

Con razón, se ha afirmado que el sistema presidencialista inventado en Estados Unidos ha "funcionado bastante bien en casa, pero en el extranjero ha demostrado ser básicamente un desastre" ${ }^{48}$. La idea sobre el presidencialismo, con su división correspondiente del poder, fue exportada hacia toda América Latina, por las razones insinuadas, contextualmente, en la sección I. Un poder ejecutivo unitario y fuerte. El sistema de

\footnotetext{
45 V. Hamilton, Alexander; Madison, J. y JaY, J.: El Federalista, LXX, 18/3/1788, México, D.F., Fondo de Cultura Económica, 1994, p. 298.

46 Ibíd., p. 297.

47 Chomsky, Noam: ob. cit., p.17.

48 Ackerman, Bruce: ob. cit., p. 19.
} 
gobierno presidencial, aunque distingue diversos medios de cooperación entre los departamentos gubernativos, pone en evidencia, por lo general, la insuficiencia de la colaboración entre los poderes constituidos.

El precio de la unidad del poder del presidente es muy alto. Puesto en funcionamiento el sistema de gobierno, por su naturaleza misma, emplazará al presidente en el centro de la escena política. El Congreso, que también se integra por las razones volcadas por los ciudadanos en las urnas en comicios libres, tendrá intensas dificultades para que su tarea sea percibida por la comunidad de ciudadanos. En la Argentina, en Brasil y en Colombia nunca llamará la atención que un ciudadano elegido para servir como diputado o senador sea convocado, horas más tarde, para fungir como "Ministro" colaborador del presidente. Si, verdaderamente, la tripartición del poder fuese evidente, no habría razones para que ello sucediere a menudo, tal como acontece. Además, la enorme "preponderancia" ${ }^{49}$ del poder del presidente conlleva, casi por definición, la debilidad del Congreso o la frustración de su papel dedicado a la representación ciudadana.

Como consecuencia de la regla divisoria del poder del Estado, los Congresos deben ser plurales y reciben su poder de las elecciones generales ciudadanas. En cambio, la jurisdicción, en especial las más altas Cortes, son colegiadas y no reciben su poder del veredicto directo de las urnas electorales. La autoridad del presidente es única; queda individualizada en la singularidad exclusiva y excluyente de una persona, sin que exista posibilidad para concebir ningún tipo de dualidad. Para el presidencialismo no hay pluralidad ni colegiatura. Su fuente de poder, al igual que la de los congresistas, sí proviene de la decisión expresada en las urnas por los ciudadanos. En tal entendimiento, Congreso y presidente, en determinado sentido principal de sus acciones políticas, compiten por la gracia del electorado.

49 LAMBERT, Jacques: América Latina. Estructura e instituciones políticas, Ariel, Barcelona, 1964, p. 500. 
Los seres humanos, muchas veces, deciden guiarse por meras creencias, las cuales no constituyen otros estados de cosas que simples asentimientos sobre un pliego de proposiciones. Las creencias no acuden a un método para demostrar de manera concluyente o plausible la veracidad de la propuesta. Bien se enseña que "en la vida cotidiana, con frecuencia, la creencia es independiente de la verdad" ${ }^{50}$. En el dominio de la política, muchas personas pueden ser movilizadas sobre la base de creencias. En el siglo xviII se echó a rodar una creencia acerca de que la unidad del poder del presidente resultaba constitutiva de una capacidad de decisión activa, diligente y solvente, por encima de la posibilidad de atribuir el mismo poder a una definida pluralidad de magistrados con igual dignidad y autoridad. Tristemente, han pasado más de dos siglos y en casi ningún país de América del Sud se ha discutido la fatalidad que se reporta de la individualidad del poder ejecutivo, excepto en la Constitución uruguaya de $1952^{51}$.

La unidad genera un líder, cuya luminosidad, en caso de suceder, algún día se apagará; la pluralidad aconseja el debate y sus luces emergen de las bases racionales del diálogo mismo. La unidad de pensamiento de un individuo ${ }^{52}$ jamás puede enfrentar, con éxito, en una sociedad abierta, a los beneficiosos

\footnotetext{
50 Bunge, Mario: Diccionario de filosofía, siglo veintiuno editores, México, D.F, 2001, p. 41.

51 Al respecto, puede consultarse Gross EspieLL, Héctor: Las Constituciones del Uruguay, Madrid, Ediciones Cultura Hispánica, 1956; Ratto Trabucco, Fabio: "La experiencia constitucional del gobierno directorial o colegiado en Uruguay", Cuadernos Constitucionales de la Cátedra Fadrique Furió Ceriol n 50/51, Universidad de Valencia, Departamento de Derecho Constitucional y Ciencia Política y de la Administración, 2005, pp. 35-75.
}

52 El ser humano alguna vez comenzó a pensar, aunque no siempre el pensamiento ha sido racional. Desde su origen de hombre pensante, el sujeto individual y soberano, no ha cesado ni cesará de hacerlo. Sin embargo, el debate crítico del pensamiento, acaso, comenzó en Grecia hace más de 2.500 años. La literatura, por su parte, contiene ejemplos abundantes de hombres que han pensado que su individualidad fuese trascendente, omnipotente y omnisciente. En 1882 Henrik Ibsen escribió en el cierre de un drama antológico: "Doctor Tomás Stockmann: Sí, sí. (reuniendo a todos en torno de sí) Lo diré ahora aquí solo. El hombre más poderoso del mundo es el que está más solo" ("Un enemigo del Pueblo", Buenos Aires, Colihue, 2010, p. 236). No hace falta decir que el epigrama del literato noruego fue escrito 
seguros de la pluralidad de ciudadanos. Quizá, la pluralidad misma constituya o revele el bien mayúsculo e irrenunciable de cualquier sistema de gobierno.

La CFA regula la cuestión con un modelo semejante, al establecer en su artículo 99, inciso $1^{\circ}$, que el presidente de la República tiene las siguientes atribuciones: "Es el jefe supremo de la Nación, jefe del gobierno y responsable político de la administración general del país". La CRFB 1988 se mantiene en la misma sintonía; en el artículo 84 se decide lo siguiente:

Compete privativamente ao Presidente da República:... II. exercer, com o auxílio dos Ministros de Estado, a direção superior da administração federal; VI. dispor, mediante decreto, sobre: a) organização e funcionamento da administração federal, quando não implicar aumento de despesa nem criação ou extinção de órgãos públicos; VII. manter relações com Estados estrangeiros e acreditar seus representantes diplomáticos.

Por su parte, la CPC 1991 dispone en el artículo 189 que el presidente es "jefe de Estado, jefe del Gobierno y suprema autoridad administrativa”.

La línea unitaria de autoridad que se desprende de las normas citadas es contundente. La jefatura del Estado incluye en su seno tareas simbólicas, ceremoniales y representativas. La jefatura del gobierno incluye la codecisión compartida con el Congreso sobre las políticas públicas, la administración del Estado y el ejercicio cotidiano de la función coactiva del poder. La tendencia personalista del presidencialismo es innegable.

Ahora bien, no sólo se define la autoridad gubernativa y estatal, porque, en resumen, todo el proceso constitucional queda liderado por el presidente. ¡Presidente es sinónimo de autoridad! Un director absoluto de las lides fundamentales del Estado y su gobierno correspondiente, con poco o nulo espacio

para otro contexto, pero ello no le quita fuerza expresiva ni utilidad en mi propia dicción, cuando trato de hilvanar la unidad del poder individuada en un solo hombre. 
para comprender las debilidades, manifiestas o latentes, que tiene todo ser humano.

Postulo que, al instituirse en una sola persona, ello autoriza a corregir la denominación del presidencialismo por "monopresidencialismo". Un instituto constitucional ejercido por una sola persona, el "monopresidente". Un vehículo constitucional de una sola rueda, si funciona la rueda presidencial, con arreglo a sus inmensos poderes, arrasa con toda energía suprema contra cualquier otra autoridad constituida, en especial, legisladores y jueces. Resulta parecido, en algún sentido, al monarca, un "rey" $" 53$ que concentraba o deseaba concentrar todo el poder del Estado. En cambio, si no funciona la única rueda presidencial, el vehículo constitucional no avanza, queda a la vera del camino y, por lo general, con toda la ciudadanía expectante y desesperada por la institucionalidad precaria, sombría y que borda el desasosiego comunitario.

El presidente no ejerce solo el poder político institucionalizado; también cogobierna con el Congreso la judicatura y los restantes órganos constitucionales. Aunque las Leyes fundamentales distribuyen el poder en diferentes ramas gubernativas, es el presidente el sujeto que dirige el proceso constitucional. El sistema de gobierno presidencial es un modelo en el que existe la separación de funciones gubernativas, pero la hegemonía de la autoridad ejecutiva tiende a debilitar y muchas veces pulverizar el propio principio divisorio del poder. Además, la autoridad ejecutiva suprema del Estado, el presidente, es quien asume la responsabilidad directa ante la ciudadanía que lo eligió. La misma noche en que se conozca el resultado de la elección, sin dudar, prometerá, en su primer discurso como primer "oficial del pueblo", que él es el presidente de todos los ciudadanos, y ponderará, incluso, las virtudes de la minoría que no lo escogió en su preferencia electoral.

53 Proudhon, Pierre-Joseph: "Que la Présidence, c'est la Monarchie", en Melanges. Articles de Journaux (1848-1852), Premier Volume, Paris, Librairie Internationale, 1868 [1848], pp. 160-164. 
Desgraciadamente, la CPC 1991 contiene una regla que merece ser acatada, pero que se encuentra en las antípodas teóricas aquí especuladas. Así, en el artículo 188, se ordena que "El Presidente de la República simboliza la unidad nacional". La cualidad de "nacional" jurídicamente resulta inasible e indefinible. En lo sustantivo, la "unidad", encerrada en una persona, la del presidente, no es defendible en términos políticos, porque la concepción unitaria del Estado dependerá siempre de la correspondiente unidad política de los ciudadanos que integran el pueblo. A decir verdad, con enunciados como el criticado, se desvanece cualquier posibilidad para eliminar la conjura que comporta la concentración de un poder hegemónico en la unidad presidencial. Un oficial del pueblo elegido de manera directa para cumplir la tarea ejecutiva no parece representar el "baluarte de una auténtica democracia" 54 , dado que su "elemento autocrático relativamente fuerte" 55 quedará en evidencia por la propia unidad indiscriminada en la concentración de sus potestades.

Es sabido que en el sistema presidencial hay tres poderes institucionales separados: el ejecutivo, el legislativo y el judicial. El presidencial y el congresual son órganos cuya integración siempre es el resultado de elecciones de los ciudadanos que integran el pueblo. El presidente y el Congreso, en el ámbito de sus respectivas competencias, ejercen un poder político eminente. La lucha por dicho poder político muestra los avances, retrocesos y vacilaciones del régimen presidencial. Dado que el presidente no puede disolver jamás el Congreso -ni siquiera de juzgarlo conveniente políticamente-, la estabilidad o regularidad del modelo suele quedar circunscrita, en mayor o menor medida, a las reales condiciones de que el titular del ejecutivo disponga para trazar y cumplir sus políticas gubernativas. Un itinerario azaroso del presidente y la comunidad de los ciudadanos que dispuso elegirlo por cuatro años, siempre que el "príncipe" no

\footnotetext{
54 En contra: WeBer, Max: Escritos políticos, t. II, México, D.F., Folios, 1982, p. 307.

55 V. KelSEN, Hans: Teoría general del Derecho y del Estado, México, D.F., UNAM, 1958, p. 358.
} 
incurra en conductas desastrosas e inconstitucionales y que éstas ofrezcan la posibilidad de enhebrar un juicio político.

Los presidentes de la Argentina, de Brasil y de Colombia, según se ha visto líneas más atrás, son elegidos por apelación a los sistemas electorales mayoritarios. Señalo, también, líneas más atrás, que no dispongo de preferencia por ningún sistema electoral y que además la experiencia mundial demuestra bondades y fatalidades en cada uno de ellos. No obstante, la mayoría de los países del mundo con estabilidad institucional utilizan uno de los dos sistemas. Jamás son mezclados el "sistema de representación de fuente o derivación proporcional” y el "sistema electoral de fuente o derivación mayoritaria". Pienso, por ejemplo, en la institucionalidad estadounidense y en la arquitectura alemana; en el primer caso, el sistema mayoritario funciona a pleno, mientras que en el segundo sobresale el sistema de representación proporcional.

Los Congresos de la Argentina, Brasil y Colombia, en una ingeniería fatal, mezclan los sistemas electorales para alcanzar su composición. Nadie recuerda que para alcanzar tal decisión, en los momentos constituyentes respectivos, los decisores hayan discutido sobre la búsqueda del Santo Grial. Probablemente, "así, sucedió" son dos palabras que cualquier sudamericano descubrirá con resignación: la fuerza normativa de lo fáctico que, por regla, favorece a los más fuertes o a los más poderosos.

Los senadores en la Argentina duran seis años en sus mandatos, la Cámara se renueva por tercios cada bienio y sus integrantes son elegidos por sistema mayoritario. En Brasil los senadores disponen de ocho años de mandato, son elegidos por voto mayoritario, y la Cámara se renueva un tercio cada cuatro años y los dos tercios restantes al cabo de ocho años. En Colombia los senadores duran cuatro años en su encomienda, la Cámara se renueva integralmente también cada cuatro años y sus miembros son electos por voto mayoritario.

En la Argentina los diputados duran cuatro años en su mandato, son elegidos por el sistema de representación electoral, 
y la Cámara se renueva, por mitad, cada dos años. En Brasil se escoge el mismo sistema electoral de representación proporcional para seleccionar diputados: los legisladores duran cuatro años en sus funciones. En Colombia los diputados también duran cuatro años en sus mandatos y son elegidos por el mismo sistema de representación proporcional.

Sinceramente, se hace difícil disfrutar de esta arquitectura constitucional e imaginar un "final feliz". Así presentados los modelos para la integración de los Congresos argentino, brasileño y colombiano, respectivamente, son sistemas electorales que se muestran, al menos, como maquinarias perezosas, porque al momento de perseguir consensos congresuales todo será complejo. En especial, respecto de las Cámaras de representantes o diputados. El presidente de la República, que fue elegido por un sistema mayoritario, sobre quien se ha descargado la unidad y el liderazgo del proceso constitucional, deberá realizar una odisea para conseguir el respaldo de los representantes del pueblo, dado que la fragmentación constituye una clave de la integración del Congreso. Si, en cambio, tuviese respaldo congresual, por regla se producirá la devaluación de este órgano a raíz de la energía de la presidencia.

Además, las elecciones para escoger presidente de la República son cada cuatro años y los Congresos se renuevan parcialmente, como sucede en la Argentina, por bienios en su Cámara de Diputados o cada dos años un tercio de su Cámara de Senadores, o, parcialmente, como sucede cada cuatro años en el Senado de Brasil, con un tercio de sus miembros. Todas estas diferencias inciden con descomunal agudeza en las circunstancias en las que el presidente deba perseguir la conformación de una mayoría congresual para sancionar una ley o para hacer una designación que requiera acuerdo congresual. La ausencia de acuerdo en el Congreso puede acarrear el inmovilismo del presidente, quien muchas veces se siente tentado para acudir a todo tipo de mecanismos para impedir o para restaurar el daño sobre su gobernanza.

Las tareas del presidente, ya sea para estimular políticas públicas, o para rechazar políticas, son cumplidas merced a un 
cúmulo de atribuciones reguladas en las Leyes fundamentales. Los campos básicos sobre los que se desarrolla la tarea de un presidente se cumplen sobre la legislación y sobre la nominación y designación de servidores públicos que cumplirán sus funciones en distintos estamentos de la estructura burocrática del Estado.

En todo Estado constitucional existe un contexto de producción y otro contexto de realización del Derecho ${ }^{56}$. Usualmente, se atribuye a los presidentes la facultad para reglar las leyes congresuales. Puestas las leyes en el mundo por los congresistas, se le atribuirá al presidente la capacidad para ejecutarlas y para realizarlas. Los presidentes son los encargados de implementar una ley. Una gran cantidad de instrumentos legales, luego de su formación y de su promulgación, requieren de una tarea minuciosa para su reglamentación y, así, empalmar, rectamente, el itinerario de su realización con seguro acatamiento. Esta atribución se le encarga al presidente, quien en la práctica constitucional demuestra una importancia decisiva, porque -repito- gran cantidad de leyes lo exigen, dado que no son de aplicación inmediata y requieren reglamentación ejecutiva.

También el presidente goza de la capacidad innata para enviar proyectos de ley al Congreso. Muy bien se ha advertido que en estos casos la autoridad del Congreso, aunque no tiene restricciones por vía del principio constitucional, en la práctica es un "poder de guardabarrera" ${ }^{57}$. Además, la iniciativa legislativa del presidente puede responder a una promesa asumida

\footnotetext{
56 La Constitución es producida y concretada por el poder constituyente; el resto de las reglas jurídicas de alcance general son creadas por el Congreso federal o el departamento ejecutivo; excepcionalmente, por el poder judicial. Producida la norma, deberá sobrevenir su acatamiento, es decir, su realización tanto por los ciudadanos como por los servidores a cargo de los poderes del Estado. La realización del Derecho producido a partir de la Constitución, en especial, las leyes de Congreso, frecuentemente, requieren de la actividad realizadora del presidente para su implementación. La realización del Derecho constitucional será siempre, pues, concreción o ejecución de Derecho creado.

57 Shugart, Matthew S. y Mainwaring, Scott: "Presidencialismo y democracia en América latina: revisión de los términos del debate", en AA.VV.: Presidencialismo y democracia en América latina, Buenos Aires, Paidós, 2002, p. 57.
} 
en la campaña electoral, motivo por el cual el impulso será decisivo y determinante. Un porcentaje altísimo calculado sobre el total de leyes sancionadas por el Congreso residen en la autoría, intelectual e institucional, del órgano presidencial. En este sentido, el presidente es un colegislador.

La posición de colegislador del presidente, quizá, podría desmentirse con el hecho de que en el sistema parlamentario, efectivamente, su desarrollo y supervivencia se encuentra mucho más sujeta a la naturaleza satisfactoria o insatisfactoria de la legislación. A poco que se escrute, se descubrirá que no resulta de este modo. Esto es así no sólo por el veto del que dispone el presidente; la independencia del Congreso, en el sistema de gobierno presidencial, aunque se encuentre asegurada por la Constitución, en la práctica queda alineada con el mérito de que disponga el presidente. ¿O son conocidas muchas democracias presidencialistas en las que el Congreso legisla de manera independiente a los deseos, manifiestos o latentes, del presidente?

Todo proyecto de ley sancionado o elaborado por el Congreso, para gozar de existencia jurídica, deberá contar con la anuencia o el rechazo del presidente; el orden constitucional puede contemplar un plazo para esta decisión del poder ejecutivo, pero ello no varía la naturaleza del príncipe ejecutivo en su rol como colegislador.

Al mismo tiempo, el presidente asume prerrogativas relacionadas con el cambio constitucional. De esta forma, envía al Congreso proyectos de reforma de la Constitución, como sucede en Brasil y Colombia, órdenes jurídicos en los que la variación puede ser realizada por el Congreso. En la Argentina, que es muy infértil para el cambio constitucional, el presidente puede impulsar la tarea de naturaleza preconstituyente a cargo del Congreso.

Además, para cumplir su tarea elemental, los presidentes dictan reglamentos, que son piezas jurídicas decididamente legislativas, aunque ceñidas al ámbito de la administración pública. 
Eso no es todo: las Constituciones también atribuyen a los presidentes la posibilidad de dictar decretos, en casos de urgencia y necesidad (DNU), instrumentos que ensalzan y cubren una actividad de naturaleza legislativa reservada, por la Constitución, al Congreso. La concesión de esta atribución tiene entidad para desmadrar por completo cualquier teoría sobre la separación de funciones gubernativas. Lamentablemente, se encuentran encajados en la CFA, en cuyo texto se les ha reconocido estatus; el mal se ha profundizado con la reglamentación legal ${ }^{58}$ del instituto: estos instrumentos tenebrosos del debate público sólo dejan de existir con el rechazo conjunto de la Cámara de Diputados y de la Cámara de Senadores ${ }^{59}$, cuando el sentido común indica que debería bastar con el rechazo de solamente una de las Cámaras congresuales para eliminar la patología de los DNU o especie semejante del orden jurídico del Estado. Estos instrumentos también existen en Colombia ${ }^{60}$ y en el Derecho constitucional brasileño, pero bajo el apodo de "medidas provisorias"61.

Otra cuestión que profundiza los poderes del presidente es el poder de veto, porque se trata de una exposición de un poder legislativo de firme naturaleza negativa e impeditiva. Constituye el rechazo parcial o total de una ley sancionada por el Congreso. No importan los presagios ni las admoniciones. Si el presidente no quiere una ley, la veta. Luego podrá el Congreso, con mayorías agravadas, insistir con el proyecto legislativo, pero el "monopresidente" ya ha emitido su palabra pública, al decidir su rechazo en el temperamento adjudicado al veto. El veto presidencial sobre un proyecto de ley se encuentra regulado en los artículos 78, 80 y 83 de la CFA; en el artículo 84, apartados V, de la CRFB 1988; y en el artículo 200, inciso $1^{\circ}$, de la CPC 1991.

\footnotetext{
58 Ley 26.122 (2006).

59 Los "decretos por razones de necesidad y urgencia" son reglamentados en el art. 99, inciso $3^{\circ}$, de la CFA.

60 La especie de los "decretos con fuerza de ley" florece, por ejemplo, en el art. 215 de la CPC 1991.

61 Su reglamentación se contiene en el art. 62 de la CRFB 1988.
} 
También en materia de nominaciones, debe pensarse que en países como la Argentina, Brasil y Colombia son necesarios varios miles de funcionarios para cubrir todas las áreas a cargo de sus poderes ejecutivos. Para designarlos se ejercitan los poderes del presidente, al igual que en el caso de la designación de sus colaboradores, de un modo absolutamente discrecional, más allá de la reglamentación sobre las carreras administrativas, sin otro costo que la censura política por la ineficacia o inopia del servidor. ¿O alguien imagina que el presidente no dispondría sobre quién ha de ser la persona a cargo de la recaudación y fiscalización de los ingresos tributarios o aduaneros, o a cargo de la agencia responsable de los servicios de inteligencia del Estado?

Otras designaciones, si bien deben ser realizadas también el presidente, precisan del acuerdo congresual. Por lo general, los jueces requieren para su nombramiento de la aquiescencia o confianza del Congreso, en ocasiones luego de un examen en el Consejo de la Magistratura. Lo mismo ocurre para las jerarquías de las Fuerzas Armadas; no basta que el presidente sea, por regla, su comandante en jefe. Asimismo, son nominados por el presidente los miembros del servicio a cargo de las relaciones exteriores y diplomáticas del Estado, pero se precisa de una conformidad del Congreso en el pliego respectivo. El mismo proceso ha de seguirse para la designación de los funcionarios encargados de determinados órganos de control y fiscalización.

Continuando con las facultades supremas de este "monopresidente", puede convocar la realización de sesiones extraordinarias de los Congresos. Se trata de una facultad desmesurada, porque interviene, directamente, en el campo delicado de la autonomía del Congreso y afecta su agenda política.

El Congreso también puede delegarle atribuciones propias al presidente. Sucede en la Argentina (art. 76, CFA). También hay delegación legislativa en Colombia (art. 150, inc. 10 ${ }^{\circ}$, CPC 1991), e igual suceso se verifica en la CRFB 1988 (art. 68). 
Dada la naturaleza federal de los Estados, en la Argentina y en Brasil el presidente de la República puede disponer la intervención a un ente de la federación. Lo autoriza el artículo 99, inciso 20, de la CFA, en caso de receso del Congreso, y el artículo 88, apartado X, de la CRFB 1988.

En paralelo a los poderes constitucionales reglados, el presidente también posee poderes de influencia política notables, no sólo sobre los congresistas partidarios ${ }^{62}$ de su propia fuerza o movimiento, sino también con respecto a los congresistas que se encuentran en la oposición política. En virtud de que no se trata de poderes reglados, no resulta posible aquí su tratamiento, ante la ausencia de evidencia normativa. Sin embargo, en más de dos siglos de práctica del presidencialismo, la escasa influencia del presidente sobre el Congreso marca, por lo general, un estancamiento o parálisis de la actividad política. Contrariamente, el ejercicio de atribuciones presidenciales eminentes tenderá al abuso y también indicará una crisis en la separación de los poderes constitucionales.

Tampoco puede merecer tratamiento la influencia que los presidentes ejercen sobre los servicios de comunicación audiovisual, porque no comprende una situación reglada, en detalle, en la Ley fundamental. Al inventarse la presidencia en el siglo xvIII, sólo existía la prensa escrita. Hoy el discurso de los presidentes puede ser divulgado y transmitido, al instante y a cualquier lugar del mundo, por fuentes orales, escritas o audiovisuales, en diversos tipos de soportes.

El abuso del presidente en el manejo de los servicios de "comunicación" 63 no sólo insinúa una debilidad de la democracia, porque devalúa el derecho a la comunicación: un bien colectivo y fundamental de la comunidad. Hará que colapse, más temprano que tarde, cualquier posibilidad de deliberación

\footnotetext{
62 Shugart, Matthew S. y Malnwaring, Scott: ob. cit., p. 49.

63 La CRFB 1988, en su art. 220, inc. $5^{\circ}$, dispone que los medios de comunicación social no pueden ser objeto de monopolio u oligopolio.
} 
genuina en el auditorio ciudadano. De la misma manera que un presidente podría abusar del derecho a la comunicación, una hegemonía en la propiedad de los medios (radio, tv, prensa escrita) podría volcarse, con semejante naturaleza, contra las políticas presidencialistas. Los sistemas de gobierno, incluido el presidencialismo, observan una notable reducción del "peso y la esencialidad de los partidos políticos" ${ }^{64}$, circunstancia que obliga a estos últimos a transformarse y adecuarse a los influjos de la "video-política".

Por último, aunque resulte complejo agotar la lista, el presidente debe cumplir con su tarea individual e indeclinable de representación del ente comunitario ante la constelación de Estados que existen en el mundo. También ejerce la representación del Estado en el seno de las organizaciones supraestatales como la ONU, la OEA, la UNESCO, etcétera. En dicho ámbito estelar, el presidente debe enhebrar y cultivar las relaciones exteriores de su Estado, porque resulta ser el encargado constitucionalmente elegido para cumplir con la misión.

El presidencialismo, de acuerdo a lo antevisto, puede ser comprendido como un sistema de gobierno adoptado por las democracias constitucionales en el que la representación ejecutiva se imputa e instituye en un órgano capital y monista. Su titular, el "monopresidente", es de esperar que sea elegido en comicios libres, auténticos, competitivos, transparentes e informados, en los que se persigue una suerte de legitimación originaria en las urnas, por lo general, una irresistible mayoría absoluta y con arreglo en el sufragio universal de los ciudadanos. Asimismo, la determinación fija del período de la gobernanza del presidente es una clave, ya que empleará buena parte de su tiempo en buscar su reelección para un nuevo período.

El presidente liderará, aun sin que él lo desee o contra sus propias convicciones, el proceso constitucional y ejercerá, en simultáneo, la jefatura del Estado, la del gobierno, la de las

64 SARTORI, Giovanni: Homo videns. La sociedad teledirigida, Buenos Aires, Taurus, 2000, p. 110. 
Fuerzas Armadas y la de la administración del país. Los ministros son más colaboradores de su propia "gestión" gubernativa que funcionarios apropiados del Gobierno, desde que, por regla, requieren la confianza, exclusiva de la autoridad suprema ejecutiva tanto para su nominación como para su remoción. La concentración de funciones en la persona del individuo elegido presidente constituye una nota elemental del sistema.

Así, el presidente, en su rol de director absoluto y regio del proceso constitucional, reglamentará las leyes, dictará decretos con fuerza de ley, administrará el Estado, podrá tener una impronta en la jurisdicción administrativa, nominará magistrados y embajadores y, por cierto, tendrá una fuerte iniciativa para proyectos de ley, además de poseer una tarea de colegislador, dado que promulga las leyes, se yergue en árbitro del proceso legal, porque tiene capacidad de veto, y hasta posee una suerte de codecisión política sobre una reforma constitucional. Restan añadir los poderes de crisis que tienen los presidentes para remediar las emergencias infinitas de nuestros países, que nacieron con la mácula de las deudas externas de su erario público por su naturaleza colonial. En tales casos, el centro del debate siempre girará respecto del hecho de los poderes del presidente y si ellos hacen pie en la Constitución o se apoyan fuera de ella.

Por cierto, me he olvidado de la notable influencia que tendrá su autoridad, mientras dure la energía de su poder supremo. Finalmente, el Congreso no puede desbancar al presidente, no hay voto de confianza parlamentario y el juicio político para la destitución del "príncipe" constituye una cuestión más cercana a la heurística constituyente que a la realidad efectiva que se suscita, porque requiere de mayorías congresuales extraordinarias para su impulso y concreción.

Recientemente, Diego Valadés ha presentado una tipología original y sesuda del presidencialismo en América Latina. Este jurista mexicano distingue tres modelos: el "tradicional", el "transicional" y el "democrático". Así, denomina presidencial 
"tradicional" al modelo que mantiene la concentración del poder en la persona del presidente. A su juicio, la preservación de este modelo tradicional implicará costos sociales de inequidad e inseguridad, costos políticos de ineptitud y corrupción, y costos económicos de improductividad y rezago ${ }^{65}$.

Llama modelo presidencial "transicional" al que se corresponde con una etapa que se sitúa entre la posición tradicional, reacia a los cambios institucionales y el modelo democrático hacia el cual podría evolucionar. El modelo transicional tiene como propiedades distinguidas la adopción normativa de instrumentos de control jurisdiccional y político, con responsabilidades para los titulares de los cargos públicos, y se caracteriza porque los controles sociales, en especial los de índole electoral, ya se encuentran consolidados ${ }^{66}$.

Valadés juzga que se alcanzará un modelo presidencial "democrático" cuando se pase de los enunciados formales a la realización efectiva de las normas en materia de controles jurisdiccionales y políticos. Por ende, se estará ante un sistema que ha superado la concentración de facultades en una sola persona, en el que las decisiones gubernamentales son objeto de deliberación en un gabinete con facultades constitucionales y los ministros que lo integran están sujetos a responsabilidades políticas. En el modelo democrático, la "norma y la normalidad coinciden" ${ }^{67}$. La regulación normativa hecha realidad, un poder ejecutivo discernido y controlado, es congruente con la realidad normada por la regla.

El distinguido jurista mexicano ha interpretado que la mayor parte de los Estados de América Latina se encuentran en la fase transicional, y solamente Chile, Costa Rica y Uruguay mostrarían "instituciones plenamente operativas que permitan

\footnotetext{
65 VALADÉS, Diego: “Formación y transformación del sistema presidencial en América Latina...", ob. cit., p. 842.

66 Ibíd., p. 843.

67 Ibíd., p. 844.
} 
hablar de un sistema presidencial democrático"68. Hay una clave que recorre toda la tipología: califica como "democráticos" sólo tres regímenes constitucionales sobre más de 20. La realización del aludido "presidencialismo democrático" no se encuentra ni en la Argentina ni en Brasil ni en Colombia.

De acuerdo con la tesis por la que se decide este escrito, según se da cuenta más atrás en la sección II, restaría, ahora, redondear algunas ideas en torno al conjunto de atribuciones del presidente y los riesgos o las ventajas que para la estabilidad o inestabilidad jurídica encierra la decisión por este modelo constituyente. En este sitio predominan las cuestiones teóricas. En todos los casos sus premisas son referidas desde la comprensión y experiencia de las realidades ofrecidas por la Argentina, Brasil y Colombia, de manera respectiva, pero para beneficio del lector aquí no haré concretas referencias normativas de sus Constituciones.

Más allá de sus propiedades congénitas, cada uno de los textos de la Argentina, de Brasil y de Colombia, con sus determinaciones específicas, permiten una orientación de sus institucionalidades republicanas. Se acude a la teoría de división del poder y se lo distingue en departamentos específicos, exclusivos y, por lo general, con funciones no compartidas. Desde la comprensión pura de la teoría tripartita del poder, aunque nunca arrojará potestades semejantes para cada departamento, se lo concibe con suficientes controles y frenos, que propondrían un determinado equilibrio y la ausencia de preponderancia de un poder constituido sobre el otro poder constituido, o sobre los otros poderes constituidos. La forma republicana se apropia de la división del poder, y por eso supone un gobierno de facultades detalladas, separadas, catalogadas y descritas, que disponen un ejercicio público y racional del poder, fruto de la decisión ciudadana. En dicha tripartición del poder en la casa republicana, el presidente tiene una porción del poder;

68 ValadÉs, Diego: El gobierno de gabinete, ob. cit., p. 30. 
una descripción de una prescripción jurídica casi autoevidente. El ciudadano, a la sazón presidente, dispone de una alícuota destacadísima del poder republicano constituido.

Se atribuye el cargo de presidente junto con la institución de sus poderes ejecutivos inherentes, aunque también disfrutará de poderes de naturaleza legislativa y hasta jurisdiccional. El poder gubernamental del presidente, a diferencia del poder legislativo y de las altas cortes de justicia, resulta ejercido de modo individual por una sola persona. La individualidad de la institución presidencial, que sólo puede fungirse en la persona del ciudadano elegido, no es una mera concepción de laboratorio, porque posee profundas implicancias jurídicas. Independientemente del hecho de que los actos del presidente deberían ser avalados o auxiliados por sus ministros, deseo resaltar la individualidad del cargo como un elemento central que hace a la concepción estructural y a la dimensión funcional del servidor público. El poder ejecutivo individualizado en el presidente es el único poder de esta naturaleza recogido por las Constituciones, lo que da lugar a la unidad del poder presidencial. Esa naturaleza unitaria es la que inhibe e impide cualquier intento de racionalización.

La asfixiante individualidad de las atribuciones del "príncipe republicano" denota la inmediata necesidad que reclama la "democratización del poder presidencial" ${ }^{69}$. Ello podría suceder, quizá, con un gobierno de gabinete de ministros que tuviese personalidad, iniciativa, anclaje congresual y responsabilidades propias $^{70}$. También, con la colegiatura de la institución ejecutivopresidencial, y conferirle una naturaleza plural, al estilo de la Constitución de Uruguay de $1952^{71}$. Cualquier cambio requerirá

69 Ibíd., p. 123.

70 Ibíd., p. 124.

71 V. Gross Espiell, Héctor: ob. cit., pp. 109-121 y 371-462.

Constitución de Uruguay, 1952.

"Art. 149. El Poder Ejecutivo será ejercido por el Consejo Nacional de Gobierno". 
de una enmienda o reforma constitucional en los países elegidos, aunque comparto la idea que señala con pesadumbre que la "crítica frontal al presidencialismo está perdiendo espacio en América Latina" ${ }^{72}$. Una destacada complacencia con el sistema de gobierno presidencialista se sitúa, quizá, en la propia raíz de confrontación, litigio y ausencia de neutralidad, que se amontonan en las cualidades del modelo estudiado.

En el cuerpo del sistema de gobierno presidencial, que se integra por la unidad y la concentración de funciones, se encuentran sus propias posibilidades para garantizar la estabilidad o inestabilidad del orden jurídico creado. Repárese, por cierto, que la anatomía del sistema presidencialista y su fisiología tienen entidad para marcar la propia regularidad del orden jurídico estatal en que hunde la disposición de su cuerpo.

Emplearé, con ajustes y adaptaciones, la siguiente noción de "estabilidad"73. Así, entiendo que un determinado sistema de gobierno es estable cuando los estados de cosas vinculados con el "ejercicio institucional del poder", conglobado con sus controles respectivos, posee la tendencia a realizar la regla constitucional, al exhibir un cumplimiento bastante eficaz. La tendencia aludida se mantiene, como explicación eficiente, durante la vigencia de la Ley fundamental, incluida su variación, gracias al proceso de cambio inscrito en ella misma.

Se puede apreciar que la noción se relaciona con un orden constitucional determinado, el que puede enfilarse por el

“Art. 150. El Consejo Nacional de Gobierno está integrado por nueve miembros elegidos directamente por el pueblo, conjuntamente con doble número de suplentes, por el término de cuatro años, con las garantías y conforme a las normas que para el sufragio se establece en la Sección III, considerándose la República como una sola circunscripción electoral. Para la elección de Consejeros Nacionales, se acumularán los votos por lema, quedando prohibida la acumulación por sublemas".

Sobre este asunto también se puede leer el ensayo de Ratto Trabucco, Fabio: ob. cit., pp. 35-75.

72 Alegre, Marcelo: "Por una democracia sin presidentes", ob. cit., p. 43.

73 Garzón Valdés, Ernesto: Derecho, ética y política, Madrid, CEPC, 1993, p. 606. 
presidencialismo o el parlamentarismo. También la aplicación de la noción de "estabilidad" queda juramentada con un contexto histórico fijado por el ciclo constituyente e imperativo de una Ley fundamental. La relatividad de la noción, además, implica que su aplicación a un texto determinado dentro de un contexto fijado no permite conjeturar una mejora o un empeoramiento de las condiciones de existencia de los ciudadanos. Constituye un hecho comprobable que en el mundo entero las democracias parlamentarias muestran mayores ejemplaridades que el presidencialismo para ordenar el ámbito de las libertades, de la orientación de la igualdad y hasta cierta solidaridad en la comunidad. Sin embargo, ello no debería determinar por completo la idea sobre la estabilidad constitucional de un orden jurídico.

No hay estabilidad sin gobernabilidad. La estabilidad de cualquier modelo presidencial o parlamentario demuestra las posibilidades sinceras que ha de poseer la gobernanza. La gobernabilidad de una democracia constitucional merece ser encauzada dentro del marco propiamente previsto por el orden constitucional (presidencial o parlamentario) y en un contexto de legitimación razonable.

El gobierno constitucional se integra por el conjunto de órganos que ejercen el poder del Estado. Así, la tarea de gobernar será la tarea de construir hegemonía. Se intentará concretar la angustiante confluencia entre los intereses individuales y los colectivos hacia un interés general predefinido de manera abierta en el programa instituido por la Ley fundamental. En caso de seguirse la fórmula clásica que indica que "hegemonía" es igual a "la suma de coerción más consenso", el problema radicará en saber cuál de ambos términos tendrá primacía en la construcción. Si predomina determinado consenso, será una forma bastante democrática. Si, por el contrario, prima la pura coerción, el desliz será hacia un gobierno autoritario.

La democracia constitucional reposa en el pluralismo. Esto hace que en determinado sentido todos deben sostener la idea del auditorio plural; caso contrario, se debilita o pulveriza. El 
pluralismo político debe cobijar todas las opciones en su interior y a la luz del día, incluso las posturas neutrales. La búsqueda de un ganador, que ejerza como presidente, no favorece ni a quienes no lo apoyaron ni a los neutrales. Quien gane la elección tendrá la tentación de conducir al país como lo aconsejan las convicciones de su mismidad. La gobernabilidad queda en duro trance.

Para gobernar, el presidente requiere de mayorías extendidas. Si las posee, construirá hegemonía suficiente; si no, tendrá una debilidad que puede ser extrema. En la Argentina, no basta una elección para triunfar políticamente. En los dos primeros años de mandato del presidente electo, la Cámara de Diputados mantendrá un $50 \%$ de su composición anterior. El Senado, durante los primeros dos años del mandato del presidente elegido, mantendrá los dos tercios de su integración anterior. En la Argentina, no basta un acto comicial para cargos electivo-populares para consolidar un triunfo político. En Brasil, también coinciden las elecciones, excepto la del Senado. En el modelo colombiano, en cambio, las elecciones para congresistas y presidentes son coincidentes.

He evitado, a propósito, analizar la mixtura de sistemas mayoritarios para elegir presidente y sistemas de representación proporcional para elegir un fragmento del Congreso. La combinación de los sistemas no fortalece la unidad del poder del presidente. Bastaría pensar, por de pronto, que en el único país del mundo en el que el presidencialismo funciona con determinada eficiencia (EE.UU.) -y que por ello lo configura en un sistema "singular y único"74-, no hay combinación de los modelos electorales: todo es resultado de la aplicación de un sistema electoral de sesgo mayoritario para la composición del ejecutivo y la composición del Congreso.

Se podría imaginar, por ejemplo, que la existencia de varias posturas en la democracia constitucional favorecería un debate

74 Dalh, Robert: ¿Es democrática la Constitución de los Estados Unidos?, Buenos Aires, Fondo de Cultura Económica, 2003, p. 73. 
y la búsqueda de escenarios de consenso. El problema que se genera con el poder presidencial reside -por lo menos como se lo ejercita- en que, si dialoga, se produciría su fracaso. En consecuencia, el presidente, lejos de producir el consenso, intenta ejercer sus poderes y las presiones consabidas para que ellos no se desvanezcan.

Aunque a mediados del siglo XviII se haya advertido, con inteligencia, que la "fuerza siempre estará del lado de los gobernados" ${ }^{\prime 75}$, su concreción representa una verdadera quimera. El presidencialismo es la máxima institucionalización del poder unido en una sola persona. Por ello, alcanzar la presidencia de la República puede hacer pensar que el depósito del "ejercicio del Supremo Poder Ejecutivo en un individuo"76 lleve a imaginar a ese singular "ciudadano" que él podría ser más poderoso que los ciudadanos; quienes, mientras tanto, no se unirían en deliberación sincera para ejercer el poder que les corresponde por natural derecho propio y soberano.

En la Argentina, en Brasil y en Colombia se asiste a un proceso de acumulación extraordinaria de riqueza y de exclusión social. En los tres países los índices de exclusión social incluyen dos dígitos de ciudadanos marginados; en cambio, los pocos ricos cada día son más prósperos.

Considero que el presidencialismo constituye un formidable aparato de dominación. Hay una gigantesca vinculación entre la concentración de la riqueza y la concentración del poder ${ }^{77}$. Quienes se sienten poderosos, por el manejo y control de la producción, los negocios y las finanzas en gran escala y jerarquía, pueden sentirse tentados en dominar el escenario político. Las ilusiones de un electorado informado que adopte decisiones racionales se pueden desbancar por saboteo de las campañas políticas. Será suficiente una ingeniería que, al depender de

\footnotetext{
75 Hume, David: Ensayos morales, políticos y literarios, Madrid, Trotta, 2011, p. 66.

76 Cfr. art. 80 de la Constitución Política de los Estados Unidos Mexicanos.

77 Chomsky, Noam: ob. cit., p. 91.
} 
altos costos, sólo es susceptible de ser movilizada por individuos poderosos que desean manipular las elecciones ciudadanas.

La manipulación de una elección, en caso de acontecer, nunca puede ser igual en un sistema de gobierno parlamentario que en un sistema de gobierno presidencial. En el primer modelo, la elección no asegura la conducción del sistema, porque resulta compartido por naturaleza. En el segundo, ello sucede por naturaleza original espontánea, dado que el poder queda individualizado. Una campaña electoral para presidente, aunque implique una financiación costosa, en caso de triunfar, atesorará la conducción del proceso político.

El presidente disfruta de un poder hegemónico. La inestabilidad de sus políticas apareja siempre la inestabilidad del modelo. Hay una física del poder presidencial: si se concretan las decisiones hegemónicas, siempre con suficiente autocracia, el modelo navega, incluso en aguas profundas. Si, en cambio, su poder es inestable, dicha cualidad se transmite sin solución de continuidad al modelo. El naufragio del sistema de gobierno no es mera cuestión especulativa.

El poder ejecutivo, a cargo de un presidente, considera y planifica la cuenta del cálculo de recursos y los gastos del Estado. El presupuesto del Estado, por lo general, resulta aprobado por el Congreso, año tras año. El presidente siempre tendrá la caja del Estado en sus dos manos. Obviamente, el presidente no puede decidir cuánto han de requerir para sus gastos el poder legislativo y el poder judicial, respectivamente. Pero ninguno de estos dos órganos tendrá ni la bolsa para recaudar, ni el poder coactivo directo para afrontar sus gastos. Los poderes legislativos y judiciales, en las esferas de sus competencias departamentales, obran con autonomía para la planificación presupuestaría; aunque, por cierto, bastaría que el presidente decidiese una restricción o una limitación de sus gastos para que su capacidad operativa atravesara serios aprietos institucionales. En el presidencialismo el desarrollo del presupuesto y la ejecución del gasto tienen una dinámica capital. 
El presidencialismo estimula un modelo propicio para la corrupción. La criatura presidencial es vulnerable porque el poder se encuentra concentrado y carece de inserción congresual. El libre albedrío del "príncipe" republicano, el aparato burocrático del Estado, la obsecuencia de determinado plantel de funcionarios, la adversidad notoria y la falta de colaboración con la oposición configuran un menú que, sumado a la concentración de funciones, ocasionará, probablemente, un desvío o una ineficiencia de las funciones, así como también una ausencia de transparencia ética.

Para funcionar, el presidencialismo requiere de una hegemonía, con suficiente carga autocrática, que neutralice o postergue a su adversario político. El verbo típico del presidencialismo es "confrontar", no "pactar" ni "dialogar". Por eso, el liderazgo personal del "príncipe", su confrontación permanente y la ausencia de rendición de cuentas institucionalizada, en tiempo pertinente y espacio racional y controlado, demostraría determinado nivel de estabilidad.

Las supuestas ventajas del presidencialismo caerán muy pronto. No durará en el tiempo. ¿O acaso el lector recuerda un régimen presidencialista estable, eficiente y transparente, que haya mejorado las condiciones de existencia de los ciudadanos desde 1991 hasta 2018, en la Argentina, en Brasil o en Colombia?

\section{Comentarios finales}

Primero. La regla sobre la "distinción" de los poderes alumbra la esperanza de que el objeto del contrato constitucional se asiente en la primacía de la persona y que ésta sea elevada a primer acuerdo sobre la individuación y organización comunitaria. Si a partir de la Constitución, que concretiza la distinción y distribución de las funciones de los poderes "constituyentes y "constituidos" del Estado, son realizables múltiples itinerarios políticos, y si "poder distinguido y distribuido" significa "poder limitado", el dogma quedaría como único modo para confiar racionalmente sobre la ordenación de las existencias humanas. 
Segundo. La teoría sobre la división del poder fue pensada en Europa y concretada con la fundación constitucional de los Estados Unidos en 1787. No hay una sola persona que la haya ideado. Tampoco en la configuración del periplo constituyente, en los Estados Unidos del siglo xviii, ha existido la voz de una sola persona que la haya dispuesto. Las voces propias que participaron de su gestación han sido múltiples.

En cualquier comunidad, los ciudadanos que las integran poseen cinco clases de intereses: ambientales, políticos, económicos, culturales y biológicos ${ }^{78}$. En cada tiempo y espacio en los que los diferentes ciudadanos han desarrollado sus existencias, la preponderancia de uno o varios de los intereses observaron diferentes grados de preponderancia. No juzgo atinado dejar en el olvido el hecho de que los intereses que existieron en el nacimiento y desarrollo de los Estados Unidos fueron completamente distintos a los que se presentaron -y se presentan- en la Argentina, Brasil y Colombia, desde las cartas de sus declaraciones de independencia hasta nuestros días.

La invención de un presidente ${ }^{79}$ quizá haya funcionado en los Estados Unidos, donde la lucha entre sus clases sociales no fue de ninguna manera el criterio ordenador para orientar la comunidad. En el proceso constituyente de aquel país se desplazó a la potencia colonial, pero su comunidad no sufrió ninguna alteración, porque mantuvo intacta su "pirámide colonial" 80 . La Constitución de 1787 se corresponde con una comunidad de clases hegemónicas bien establecidas con significativas exclusiones que no parecían deducirse de la Declaración de $1776^{81}$ : esclavos,

78 Bunge, Mario: Filosofía política. Solidaridad, cooperación y democracia integral, Barcelona, Gedisa, 2009, p. 138.

79 Moore, Kathryn: The American President. A Complete History. Detailed Biographies. Historical Timelines. From George Washington to Barack Obama, New York, Fall River Press, 2007.

80 Zaffaronı, E. Raúl: Estructuras judiciales, Buenos Aires, Ediar, 1994, p. 36.

81 En Congreso, 4/7/1776. La Declaración unánime de los trece Estados Unidos de América: "Sostenemos como evidentes estas verdades: que todos los hombres son creados iguales; que 
afroamericanos, mujeres, pobres, indigentes e indios. Los postulados ideados en el origen del Estado no hicieron peligrar esta estratificación, cuya construcción era bastante sólida. Los padres fundadores de los Estados Unidos organizaron un nuevo Estado, aunque fueron "gente muy temerosa de una distribución igualitaria de la propiedad" 82 .

En el caso de la Argentina, de Brasil y de Colombia, la unción de un presidente no reporta simétricas cualidades en su inventario histórico. Al independizarse, estos tres países debieron asumir el crecimiento y el desarrollo tenaz de las existencias de sus ciudadanos, hoy todavía inconclusos y sin testimonios racionales sobre su gestación. No existe una distribución justa ni racional de los bienes yacentes o de los bienes que están a punto de crearse o que pudiesen serlo algún día.

Sería fácil echar la culpa al presidencialismo; pero el sistema, por su propia arquitectura jurídico-constituyente, no ha servido ni podría servir para construir bases racionales para el diálogo y la construcción del horizonte político de la comunidad. Desde tal comprensión, quizá, dentro de 100 años causará extrañeza leer que los ciudadanos, en 2018, disponían conferir a un solo hombre la posibilidad de ejercer una energía hegemónica, que

\footnotetext{
son dotados por su Creador de ciertos derechos inalienables; que entre éstos están la vida, la libertad y la búsqueda de la felicidad; que para garantizar estos derechos se instituyen entre los hombres los gobiernos, que derivan sus poderes legítimos del consentimiento de los gobernados; que cuando quiera que una forma de gobierno se haga destructora de estos principios, el pueblo tiene el derecho a reformarla o abolirla e instituir un nuevo gobierno que se funde en dichos principios, y a organizar sus poderes en la forma que a su juicio ofrecerá las mayores probabilidades de alcanzar su seguridad y felicidad [...] Por lo tanto, los representantes de los Estados Unidos de América [...] solemnemente hacemos público y declaramos: que estas colonias Unidas son, y deben serlo por derecho, Estados libres e independientes; que quedan libres de toda lealtad a la Corona británica, y que toda vinculación política entre ellas y el Estado de la Gran Bretaña queda y debe quedar disuelta; y que, como Estados libres o independientes, tienen pleno poder para hacer la guerra, concertar la paz, concertar alianzas, establecer el comercio y efectuar los actos y providencias a que tienen derecho los Estados independientes..." (énfasis agregado).

82 ZINN, Howard: Nadie es neutral en un tren en marcha. Historia personal de nuestro tiempo, Guipúzcoa, Hiru, 2001, p. 10.
} 
se basa en la más pura confrontación: el poder presidencial. También intuyo que generará asombro el descubrir que se instituía en un solo hombre el mando personal y ejecutivo, situación que nunca se encuentra libre del interés, del rencor y, sobre todo, del error individual. En la economía y en las finanzas hay empresas que tienen un propietario principal y él es quien ejerce su dominio. En la República el dominio pertenece a todos los ciudadanos, únicos e insustituibles, quienes deben disponer un "orden entre los asociados" 83 del condominio. De ello se deriva la incongruencia de que la actuación constitucional se atribuya a un solo ciudadano.

El presidente estadounidense dispone de un poder hegemónico, pero controlado por el Congreso y los jueces. El "príncipe", en América del Sud, mientras dure su gestión, dispondrá de un poder hegemónico con un haz de atribuciones, quizá superior al estadounidense, de acuerdo a la nomenclatura constitucional, pero los controles no serán semejantes ni -en caso de serloeficientes.

Tercero. La forma de elección del presidente instituye una cuestión relevante y paradigmática del sistema de gobierno: la utilización de sistemas mayoritarios, que cuentan además con una segunda ronda electoral, buscan el encuentro de un líder que gozaría de un amplio respaldo ciudadano. Así, el "príncipe republicano" recibirá el pronunciamiento ciudadano por un camino directo. La mayoría obtenida en la elección y la fuente ciudadana directa convencerán al líder presidencial de que su gobernación ha de conjugar a la historia misma. No será necesario ponderar la materialidad de los hechos pasados. Las inclinaciones e ideas del nuevo "príncipe republicano" son dueñas de una originalidad superior a todo lo conocido hasta entonces.

Cuarto. Jamás existirá un tiempo perdido para el presidente en su afán reeleccionista. En la Argentina y en Brasil, elegido el presidente, una de sus misiones -quizá hasta la más relevante de

83 V. Calamandrel, Piero, Sin legalidad no hay libertad, Madrid, Trotta, 2016, p. 34. 
su propio gobierno del Estado- quedará encajada en su carrera por la reelección inmediata. Así, empleará todo el aparato del Estado, incluso el coactivo y no sólo sus recursos, para cumplir el objetivo de la reelección. Una presidencia nunca es suficiente, porque los poderes concentrados sirven para preparar un horizonte de proyección distante, una segunda presidencia. Con sabiduría $^{84}$, en 2015 en Colombia se ha dispuesto, en el artículo 197 de su Ley fundamental, una prohibición de reelección del presidente con claros ribetes de naturaleza eterna; una suerte de impedimento perenne para perpetuarse en la presidencia ejecutiva del gobierno.

Quinto. La unidad de la autoridad del poder presidencial define al sistema de gobierno, pero no sólo por la atribución de la autoridad gubernativa y estatal; en resumen, todo el proceso constitucional quedará liderado por el presidente. ¡Presidente es sinónimo de unidad en el ejercicio constitucional de la autoridad! Un director absoluto de las lides fundamentales del Estado y su gobierno correspondiente, con poco o nulo espacio para comprender las debilidades, manifiestas o latentes, que tiene todo ser humano.

Sexto. Sostengo al comienzo del ensayo, en la sección II, que aquí no proyecto un modelo de sistema de gobierno. Ciertamente, la "confianza en las instituciones no se fortalece con elogios, sino con el acatamiento acompañado de una crítica racional" ${ }^{\prime 25}$. Además, no tendría originalidad plantear que la presidencia, como institución monocrática, debería ser "abolida" 86

\footnotetext{
84 La reelección presidencial es un fruto prohibido en México. La idea sobre su prohibición eterna fue consagrada en su Constitución, desde el 5/2/1917, en su art. 83.

85 Zaffaroni, E. Raúl: "Elogio del parlamentarismo", ob. cit., p. 4.

86 Lockw00d, Henry: The Abolition of the Presidency, New York, Worthington, 1884, p. 302. Recientemente, también se ha postulado "abolir la monarquía presidencial" que instituiría el vigente sistema de gobierno en Francia. Se adujo, además, que el presidencialismo es un "anomalía democrática" y que en su lugar debe instaurarse un sistema parlamentario, cuyo poder ejecutivo sea nominado por el Parlamento y responsable ante dicho órgano. V. MélEnCHON, Jean-Luc: L'Avenir en commun, París, Seuil, 2016, p. 26.
} 
y reemplazada por otro modelo plural para la función ejecutiva. Hay razones para imaginar un futuro en el que exista deliberación, altruismo, ilustración y, sobre todo, un ejercicio plural de ciudadanos que impida un apoderamiento individual del poder del Estado, más allá del prestigio que pudiese exhibir en su trayectoria un ciudadano.

Postulo que el presidencialismo debe ser democratizado. El monopolio político del sistema ahuyenta cualquier posibilidad seria para igualar a los ciudadanos en una sociedad abierta. La presidencia debe ser racionalizada en su ejercicio, tal como se la conoce. La ola democratizadora del órgano presidencial podría sobrevenir -solamente reforma constitucional mediante- por diferentes canales. La democratización del instituto debería ser interpretada como una cuestión de tiempos, porque argumentos se apilan para denostar su falta de estabilidad y su incapacidad demoledora del diálogo democrático.

La democratización del poder presidencial serviría para conjurar los abusos o desvíos autoritarios del poder presidencial. Las alternativas para evitar la naturaleza dominante del presidencialismo son de diferente naturaleza. Se puede pensar en colegiatura del órgano y asignarle una naturaleza plural de individuos. $\mathrm{O}$ en la nominación de un primer ministro y el anclaje congresual de todos los ministros, o en otras posibles formas de fusión que provengan de la experiencia del sistema de gobierno parlamentario.

Séptimo. Para cumplir su misión, el presidente debe estar dotado de una importantísima cantidad de atribuciones, que se concentrarán, con hegemonía suficiente, en la unidad indivisible y franca de su persona. Dichas facultades, en la mayoría de los casos, son explicitadas en las Leyes fundamentales. Dado que el poder es la energía fundamental en el Estado constitucional, las facultades de los presidentes deben responder, al menos, a dos acciones clave, de naturaleza asimétrica. Así, por un lado, se lo inviste para ejecutar activamente una política y, en paralelo, también se lo inviste para impedir reactivamente una política. Más 
claramente todavía, los poderes del presidente se encaminan para lograr un nuevo estado de cosas constitucionales o para inhibir o rechazar el cambio de un estado de cosas propugnado, en general, por otros congresistas. Los poderes del presidente, ya sean estimulantes o de rechazo -sin importar cuáles-, pueden ser utilizados para el progreso o para el empeoramiento de las condiciones de existencia de los ciudadanos.

El presidente goza de una gama enorme de poderes. Puede participar de la legislación ordinaria como colegislador, ya sea porque envía iniciativas al Congreso o porque promulga las leyes. La tarea legislativa, asimismo, incluye la posibilidad de dictar decretos con fuerza de ley o que el Congreso le delegue la potestad legislativa. También puede emitir proyectos sobre la reforma constitucional. Administra y gestiona el Estado con su voluntad suprema de ciudadano elegido. No hace falta recordar que maneja y presupuesta los recursos del Estado, imagina el gasto público y por eso determina las cuentas públicas de las restantes ramas del gobierno. Nombra a todos sus colaboradores y puede decidir su remoción sin otro espejo que su propia responsabilidad. Representa al Estado en lo interno y en sus relaciones internacionales. En la Argentina, además, ejerce la jurisdicción administrativa. En Colombia representa la "unidad nacional. También el presidente puede convocar al Congreso. Por si no fuera suficiente, lidera el proceso constitucional y es el actor principal del proceso político.

Octavo. El presidencialismo, cuando reduce la democracia, puede aumentar la gobernabilidad y demostrar determinada estabilidad. Sin embargo, cuando se reduce la gobernabilidad, no aumenta la democracia. Cae en pendiente el sistema de gobierno. No hay buenas razones para defender una democracia constitucional nada robusta como propone el presidencialismo, más allá de alguna ventaja que, basada sobre todo en una hegemonía fuertemente autocrática, pueda inducir una transitoria estabilidad, que siempre será sacudida por las naturalezas inclemencias de la política. Tampoco hay buenas razones para sostener un sistema, el presidencial de gobierno, 
cuya inestabilidad siempre impactará en la línea de flotación del modelo. Es falso que el presidencialismo constituya un modelo erguido para navegar en medio de tempestades institucionales. Se impone una sentencia contraria.

El modelo presidencial, entonces, propone la tormenta infinita de la confrontación política. Si la tormenta tiene éxito, desconsuela al adversario, hasta nuevo aviso. Si fracasa, no hay que prestidigitar ni hacer profecías para conocer los resultados desastrosos.

En resumen, parece cierto que la inestabilidad del presidencialismo constituirá la inestabilidad del sistema de gobierno y que la inestabilidad del gobierno parlamentario hará caer, presumiblemente, el gobierno pero no el modelo. No se puede sostener que unas bellas páginas -trátese de un modelo parlamentario o presidencial- podrán cambiar el mundo por sí solas. Sería necesaria también una ciudadanía comprometida y responsable para comprender y contribuir a la estabilidad institucional.

Noveno. El Estado constitucional se integra con una mancomunidad de ciudadanos. El ente es una asociación de dominación, cuyos poderes emanan de los ciudadanos y deben encontrarse a su servicio. Por ello, resulta intolerable e inadmisible una autoridad ejercida en nombre de un poder estatal que flotase por encima de los ciudadanos ${ }^{87}$.

Las peculiares características que tiene la elección de la presidencia, por lo general basada en el principio mayoritario, aunque entrega un poder supremo y quizá estable, no produce una protección escalonada de la minoría, quienes quedarán a la intemperie. La mayoría de los votos prueba sólo eso: un circunstancial apoyo y una oportunidad, pero no la idoneidad, la que puede llegar a faltar y mostrar los retazos de pensamientos ausentes. Dada la formación de sus poderes supremos inherentes, el líder presidencial siempre transitará su ejercicio por

87 Häberle, Peter: El Estado constitucional, México, D.F., UNAM IIJ, 2003, p. 198. 
las arenas movedizas de un poder fundado en un fragmento mayoritario de la ciudadanía.

Más de 200 años de experiencia presidencial en América del Sud hacen pensar si acaso esa supremacía del poder ejecutivo no constituye, patéticamente, la causa de las causas de la inestabilidad institucional, del sometimiento y de la vulnerabilidad social. Le pregunto al lector, en la despedida de estas letras: ¿el presidente, tal como se expresa en la Argentina, en Brasil y en Colombia, no resulta un monarca elegido, valga el contrasentido, con veleidades de un "director de pueblos" 88 con poderes hegemónicos? Si sólo son indispensables los ciudadanos, ¿puede ser cierto que el director de pueblos sea un hombre que se juzga a sí mismo como un "hombre de Estado indispensable" 89 , con poderes absolutos y que practica el monólogo presidencial?

88 ARL, Roberto: "Saverio, el cruel", Teatro completo, Buenos Aires, Losada, 2011, p. 142.

89 Ibíd. 